\title{
A Systematic Review and Lived-Experience Panel Analysis of Hopefulness in Youth Depression Treatment
}

\author{
Clio Berry ${ }^{1,6}\left[\right.$ (]) Joanne Hodgekins ${ }^{2} \cdot$ Daniel Michelson $^{3} \cdot$ Laura Chapman $^{3} \cdot$ Olga Chelidoni $^{4} \cdot$ Lucie Crowter $^{3}$. \\ Catarina Sacadura ${ }^{5} \cdot$ David Fowler $^{3}$
}

Received: 14 May 2021 / Accepted: 23 June 2021 / Published online: 6 July 2021

(c) The Author(s) 2021

\begin{abstract}
Hopefulness is arguably of central importance to the recovery of youth with major or complex youth depression, yet it is unclear how hopefulness can best be enhanced in treatment. A narrative synthesis of published and grey literature was combined with new insights from a youth lived-experience panel $(\mathrm{N}=15)$, focusing on to what extent and how specific psychological therapies and standard mental health care scaffold hopefulness as applied to depression among 14-25-year-olds. Thirty-one studies of variable quality were included in this review; thirteen were qualitative, thirteen quantitative, and five used mixed methods. Hopefulness is an important active ingredient of psychotherapies and standard mental health care in youth depression. Evidence suggests talking and activity therapies have moderate to large effects on hopefulness and that hopefulness can be enhanced in standard mental health care. However, varying intervention effects suggest a marked degree of uncertainty. Hopefulness is best scaffolded by a positive relational environment in which there is support for identifying and pursuing personally valued goals and engaging in meaningful activity.

Animated (https://www.youtube.com/watch?v=04690PdTGec) and graphical summaries (https://doi.org/10.13140/RG.2. 2.27024.84487) are available.
\end{abstract}

Keywords Hopefulness $\cdot$ Depression $\cdot$ Adolescence $\cdot$ Youth mental health $\cdot$ Psychological therapy

\section{Introduction}

Hopefulness, a long-standing object of philosophical and religious interest (Snyder, 2000), was recognized as central to psychoanalysis (Freud, 1953) and a basic-albeit elusive-ingredient in psychiatry (Menninger, 1959). Yet

Clio Berry

c.berry@bsms.ac.uk

1 Brighton and Sussex Medical School, University of Sussex, Brighton, UK

2 Norwich Medical School, University of East Anglia, Norwich, UK

3 School of Psychology, University of Sussex, Brighton, UK

4 School of Life Sciences, University of Sussex, Brighton, UK

5 Research \& Development, Sussex Partnership NHS Foundation Trust, Worthing, UK

6 Primary Care and Public Health, Brighton and Sussex Medical School, University of Brighton, Watson Building, Falmer BN1 9PH, UK hopefulness gained little further attention until the 1990s, with the creation of the cognitive model (Snyder, 2000) and the identification of hope as a core instigator and process variable within the mental health recovery movement (Schrank et al., 2008). Many have argued hopefulness underlies potentially all psychotherapeutic change (Gallagher et al., 2020; Taylor, 2000); yet this assumption is unmatched by research activity (Koehn \& Cutcliffe, 2007). Evidence of the role of hopefulness within mental health interventions remains limited, especially in youth (Gallagher et al., 2020). Hopefulness may be especially important in adolescence (Berry \& Greenwood, 2017); a key time for developing sense of self and future aspirations (Oyserman, 2001) but also of mental health vulnerability (Kessler et al., 2007). Existing interventions in youth depression, both specific psychotherapies and general standard mental health care, seemingly have only modest effects (Eckshtain et al., 2020); producing unreliable or no symptom improvement for at least $50 \%$ of youth (Bear et al., 2019) and often not improving social recovery, especially for youth with marked social and occupational withdrawal (Fowler et al., 2010). Such withdrawal is not 
only personally and economically important, but additionally predicts worsening symptoms (Goldman-Mellor et al., 2016). Therefore, increasing understandings of the interventional role of hopefulness has the potential to improve youth treatment and outcomes. This study provides an inclusive review of current evidence on the role of hopefulness in the treatment of youth depression, and combines this evidence with new insights generated by a youth panel with lived experience of mental health problems.

The cognitive model defined hopefulness as goal-directed cognition, comprising self-agency (motivation and belief in one's ability to progress towards goals) and pathways (identification of specific means of goal pursuit) (Snyder, 2000). Unlike more emotion and faith-based models (Clarke, 2003; Herth, 1991), cognitive hopefulness is especially amenable to intervention and is less confounded with symptomatology or spiritual beliefs. Hopefulness is distinct from alternative positive self and future construals, such as self-efficacy and optimism (Alarcon et al., 2013), for it predicts unique variance in health and wellbeing (Magaletta \& Oliver, 1999) and is more separable from personality traits (Alarcon et al., 2013). Hopefulness is additionally neurologically distinct from hopelessness and the two can co-exist (Jevne, 2005; Nunn, 1996). Hopefulness robustly predicts psychological, social and occupational wellbeing and reduced mental health symptoms for students (Griggs, 2017), adolescents (Esteves et al., 2013), and adolescents with chronic illnesses (Griggs \& Walker, 2016), with seemingly more predictive validity than negative self-beliefs (Berry \& Greenwood, 2017). Hopefulness is positively future-oriented and resilience-building. It protects against the impacts of adversity (Valle et al., 2006), and the negative prospective cognition (Bjärehed et al., 2010), difficulty in vividly imagining (Morina et al., 2011) and expecting positive future events (Thimm et al., 2013), and suicidality (Hirsch et al., 2012) characteristic of depression. Depression with anxiety is as common as without (Kessler et al., 2015), and comorbidity is linked to greater severity (Costello et al., 1996) and reduced recovery (Edbrooke-Childs et al., 2018). Hopefulness is therefore even more important in diagnostic complexity (Fowler et al., 2019), with such complexity especially common in youth (Blazer et al., 1994).

The increased use of positively-oriented hopefulnessfocused treatment may better enact therapeutic change through augmenting information-processing (Nelson et al., 2009) and engendering positive emotions (Schubert et al., 2020). Hopefulness can be a central feature of specific psychotherapies, for example in Hope Therapy, a form of Cognitive Behavioral Therapy (CBT) based on cognitive hope theory (Snyder, 2000). This intervention has some evidence of effectiveness, but studies in adolescence and clinical populations are very limited (Weis \& Ash, 2009). More broadly, hopefulness is arguably a feature of all psychotherapy; for successful treatment depends on the collaborative identification and pursuit of goals, and increased self-agency and pathways-thinking, for example through understanding how different therapeutic techniques can facilitate desirable outcomes (Weis \& Ash, 2009). Hopefulness is equally as relevant to standard mental health care, for example within the therapeutic relationship between patients and professionals (Berry \& Greenwood, 2015), and is linked to positive outcomes in this setting (Schrank et al., 2012). Yet, better understandings are needed as to how hopefulness is engendered in treatment and how it impacts on symptomatic and social recovery outcomes.

\section{Current Study}

Hopefulness is a promising candidate to improve both specific psychotherapies and standard mental health treatment of youth depression, yet better understandings are needed of the impacts of hopefulness in these different settings. The current systematic review aimed to generate a comprehensive synthesis of research evidence pertaining to the therapeutic enhancement and outcomes of hopefulness for youth with depression, first asking what is the evidence that hopefulness in both specific psychological therapies and standard mental health care leads to improvements in depression and social recovery for youth with major or complex depression (Research Question 1)? In addition to the need to consider different treatment settings, the context within which youth live and the diversity of their life experiences may influence the degree to which they feel hopeful (Hughes et al., 2010). Therefore, further study is needed to explore in what settings and contexts, and for whom, hopefulness is most important or effective (Research Question 2). Moreover, whilst evidence suggests hopefulness may impact on outcomes through augmenting information-processing and affect, questions remain as to what are the specific processes through which hopefulness arises and impacts on symptomatic and social recovery outcomes in youth depression treatment (Research Question 3)? The current objective was to create an inclusive synthesis, involving both published and grey literature evidence, and including research using any quantitative, qualitative or mixed methodology. In addition, lived experience participation was included as a component in the evidence synthesis in order to combine rigorous systematic review methods with experiential knowledge (Harris et al., 2016) in answering the research questions.

\section{Methods}

\section{Protocol and Registration}

This review was registered on PROSPERO on 14/07/2020 (CRD42020192701). 


\section{Study Search}

The academic databases ASSIA, CINAHL plus, PsychArticles, PsychInfo, PubMed/Medline, Scopus, and Web of science were searched between the 18th and 19th June 2020 using terms reflecting the age range, hopefulness, depression, psychotherapeutic or mental health treatment setting, and research design. Full search terms are provided in appendices (Online Appendix A). Open access thesis (EThOS, OATD, EBSCO) and grey literature (OpenGrey) depositories, and youth and student mental health organization websites (including YMCA, Student Minds, Anna Freud Centre), were searched between 1st July and 7th August 2020. Reference lists of 15 existing reviews of hopefulness for youth and/or clinical populations (see Online Appendix A) and of all included studies were screened. Screening and selection were managed using Covidence software (Veritas Health Innovation, 2020).

\section{Study Selection}

Inclusion criteria were that studies were interventional or observational, used qualitative, quantitative or mixed methods, evaluated a specific psychological intervention or standard mental health care, and had a majority sample aged 14-25 years and meeting depression caseness, irrespective of comorbidity. The upper age limit of 25 years was selected to match typical youth and youth mental health service coverage. Qualitative studies reporting a clinical sample with diagnoses explicitly described as including depression were included. Studies in any health, community, or educational setting in any geographical locality were included. Studies in non-English language, which were non-peer reviewed (not including grey literature additions) or which presented no primary data were excluded. Full criteria are provided in Online Appendix B. Study screening was conducted by five reviewers. Disagreements between reviewers was managed through all reviewers discussing the full text of each record and making a consensus decision on inclusion or exclusion, or taking the majority decision in the absence of full consensus.

\section{Data Extraction}

Data were extracted using Covidence and Excel. Extracted data included sample characteristics, design, methods, analysis, intervention characteristics (interventionist, setting, content, sessions, mode and delivery), quantitative data (absolute measure scores, standard deviations, frequencies, within and/or between group effect sizes at pre-post-intervention and follow-up as available), and qualitative data (higher order and subthemes). Intervention outcomes of interest were diagnostic and symptomatic changes in depression, captured using any diagnostic interview or other observer or self-report scale, and changes in social recovery. Social recovery can be understood as (re)gaining functioning with respect to time spent in valued and meaningful social and occupational activities (Hodgekins et al., 2015). Data extraction was performed by five reviewers.

\section{Youth Lived Experience Panel}

Fifteen youth aged 15-24 years of different genders (53\% female) and nationalities formed a lived experience consultation panel. The panel had experience of low mood or depression and many had experience of mental health treatment. The panel was recruited from a mental health NHS Trust, youth mental health and community services, and national youth and student mental health networks. Involvement was reimbursed. In two virtual Zoom (Zoom Video Communications Inc., 2020) 2-h meetings and/or email participation, the panel used self-selected images or objects to discuss their concepts and experiences of hopefulness. The panel were not involved in the process of setting the review questions or in delivering the review methods. The panel were involved in the interpretation of the review findings. Moreover, the panel were asked for their own answers to the research questions in order to provide insights perhaps not captured in research evidence reviewed. In addition, nominal group process methods (McMillan et al., 2016) were used in a research priority setting exercise. First the panel freely and independently generated future priorities for research on hopefulness for youth with major or complex depression, creating an online "idea bank" using MURAL software (Tactivos Inc DBA MURAL, 2020). After being presented with a detailed summary of the emerging review findings, the panel generated additional research priorities and then independently voted for their top 10 priority ideas. Finally, in two subgroups, the panel was asked to rank the top 10 priorities from one to 10 using imagined financial research investment from $£ 5$ million to $£ 500,000$. The two subgroups were asked to share their respective rankings and reach an overall consensus. The group were unable to reach consensus, and instead were invited to independently rank using a ranked choice question presented via Qualtrics software (Qualtrics, 2020) after the final panel meeting.

\section{Risk of Bias}

Risk of bias within each study was rated with the Mixed Methods Appraisal Tool (MMAT) (Hong et al., 2018, 2019), using the two filter questions and then five qualitative, quantitative (RCT, non-randomized or descriptive), or mixed methods criteria as appropriate. A GRADE assessment (Oxman, 2004) of bias risk across all studies was generated. 


\section{Synthesis of Results}

A narrative evidence synthesis (Popay et al., 2006) was produced, synthesizing research evidence and lived experience insights. The PRISMA statement (Moher et al., 2009) was used to prepare this report. Scientific and lived experience evidence was synthesized in relation to the research questions. Within and/or between-group effect sizes were narratively described and summarized. Qualitative data were additionally narratively described and summarized. Insights from the lived experience panel were narratively described with respect to their relevance for each of the three research questions. Verbatim quotes from lived experience experts are provided in italics.

\section{Results}

\section{Study Selection}

Five reviewers screened 8710 records (see Fig. 1) using the title and abstract. The first author screened all studies with four other reviewers independently screening 3036 records $(34.87 \%)$. Reviewer agreement regarding whether each record met inclusion or exclusion criteria was $83.64 \%$. At the full text stage, all records were screened by the first author and one of the four other reviewers independently, with reviewer agreement at $96.20 \%$.

\section{Study Characteristics and Conceptualization of Hopefulness}

Thirty-one studies were included in this review (Table 1). Thirteen studies were qualitative, 13 quantitative, and five used mixed methods. Five studies employing quantitative methods were Randomized Controlled Trials (RCT), ten were non-randomized or uncontrolled pre-post or followup studies. Six qualitative and mixed methods studies were adjunctive or sub-studies to RCTs. Nine studies were conducted in the US or Canada, six in Europe, five in the UK, and five in Australia or New Zealand. Three studies were theses (Conklin, 2009; Davidson, 2008; Hambridge, 2017); all others were published journal articles.

All studies measuring hopefulness specified it as an outcome and, in one study, an outcome (state hope) and outcome moderator (trait hope) (Conklin, 2009). Most studies used cognitive hopefulness measures and all but two studies focused on trait-level hope (Conklin, 2009; Gillig et al., 2019). All hopefulness measures used were self-report questionnaires (Online Appendix C). The lived experience panel deemed hopefulness to be both centrally important, "Hope has been really key for my mental health for a very long time", and incredibly powerful; "... a momentary moment of hope could lead to someone implementing massive change”.
The panel were asked to reflect on their concepts of hopefulness and then the fit of these with the cognitive model. The panel largely endorsed the cognitive model, stating that its goal-directed focus "definitely resonates" and emphasizing the importance and mutually reinforcing nature of selfagency and pathways thinking:

“...hope begins with having a goal and seeing a way

for it to happen out of no way."

"Not hope alone, but hope leading to action, that's really important."

"There are ways around things, different pathways, I really relate to that."

"It's hard to have the knowledge of the pathways without having the goal and drive, both pathways and the desire work together."

"I have a lot of hopefulness in life around several different areas and that this is made up of me knowing that I have the motivation to achieve things and the means (pathways) to achieve these things...If I don't have any goals to pursue that I become less hopeful"

\section{Risk of Bias Within Studies}

Studies were of variable quality, with $28.57-100 \%$ of elements rated as low bias (Fig. 2). Qualitative studies tended to be higher quality than quantitative and mixed methods studies, reflecting the high usage of non-randomized and uncontrolled quantitative designs. The items most commonly rated as high risk of bias were accounting for confounders in design and analysis and outcome data completeness (Fig. 2). The items most commonly rated as unclear were adequate data collected to answer the research questions, assessor blinding, and adequate derivation of qualitative findings from the data (Fig. 2). Studies rated as lower quality (Aubuchon-Endsley \& Callahan, 2014; Gillig et al., 2019; Isa et al., 2018; Lin et al., 2013; Sælid \& Nordahl, 2017; Smith et al., 2011; Teodorczuk et al., 2019) did not appear markedly different in reported interventional effects on hopefulness but reported larger effects on depression. Qualitative studies of lower quality (Anttila et al., 2015; Midgley et al., 2016; Watsford et al., 2013) were those which largely focused on hopes for therapy.

\section{Synthesis of Results}

What is the Evidence that Hopefulness in Both Specific Psychological Therapies and Standard Mental Health Care Leads to Improvements in Depression and Social Recovery for Youth with Major or Complex Depression (Research Question 1)?

Specific Psychological Therapies The specific psychological interventions identified were incredibly variable (see 

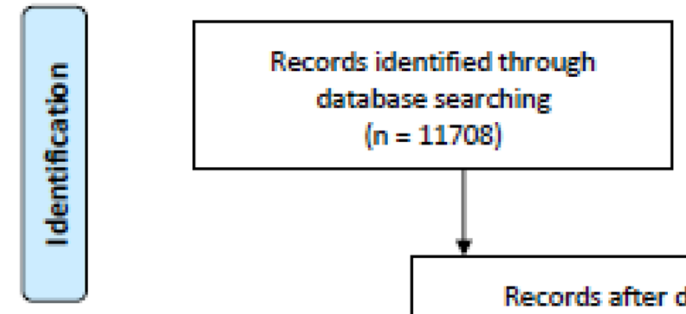

Additional records identified

through other sources

$(n=2068)$

1150 references from included studies

918 references from existing
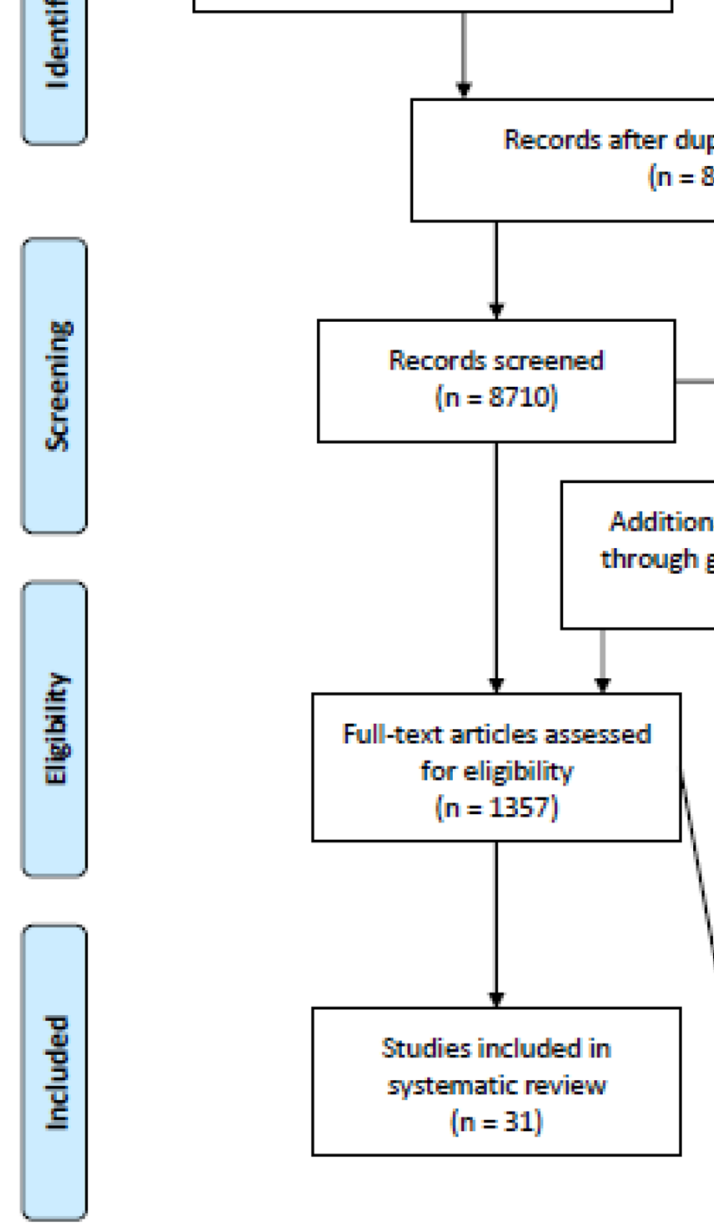

Full-text articles excluded $(n=1325)$ :

312 Did not measure/capture hopefulness in data collection or analysis

268 Focus on hopelessness

243 Population mainly/only over 25 years (170), under 14

years (29), or both (10), or age not reported (34)

202 Depression caseness not reported

83 Population majority do not have depression

56 No primary data

38 Focus on alternative positive psychology constructs

34 Full text not available

34 Not psychological intervention or mental health service setting

15 Population average below depression caseness

threshold

15 Duplicate

15 Not English language

11 Professional, family and/or carer participants only

Fig. 1 PRISMA diagram (Moher et al., 2009) of study selection

Online Appendix E), ranging from cognitive and/or behavioral-based therapies (Fowler et al., 2018; Gee et al., 2018; Isa et al., 2018; Lin et al., 2013, 2014; Metsäranta et al., 2019; Ritschel et al., 2011, 2016; Sælid \& Nordahl, 2017; Shepherd et al., 2018) to other talking (Conklin, 2009; Green et al., 2007; Leibovich et al., 2020; Teodorczuk et al., 2019), arts (Walsh \& Minor-Schork, 1997) or activity-based (Gabrielsen et al., 2019; Gillig et al., 2019; Hambridge, 2017; Smith et al., 2011) interventions. Interventions were variable with respect to duration and number of sessions
(Online Appendix E). Most interventions were provided in mental health service settings - of which all but one (Walsh \& Minor-Schork, 1997) were outpatient-or an educational setting, with two provided in residential care and two in a community nature-based setting (Table 1). Most studies involved community samples (Conklin, 2009; Gillig et al., 2019; Green et al., 2007; Lin et al., 2013, 2014; Sælid \& Nordahl, 2017; Shepherd et al., 2018; Smith et al., 2011; Teodorczuk et al., 2019), others involved clinical (Fowler et al., 2018; Gabrielsen et al., 2019; Isa et al., 2018; Metsäranta 


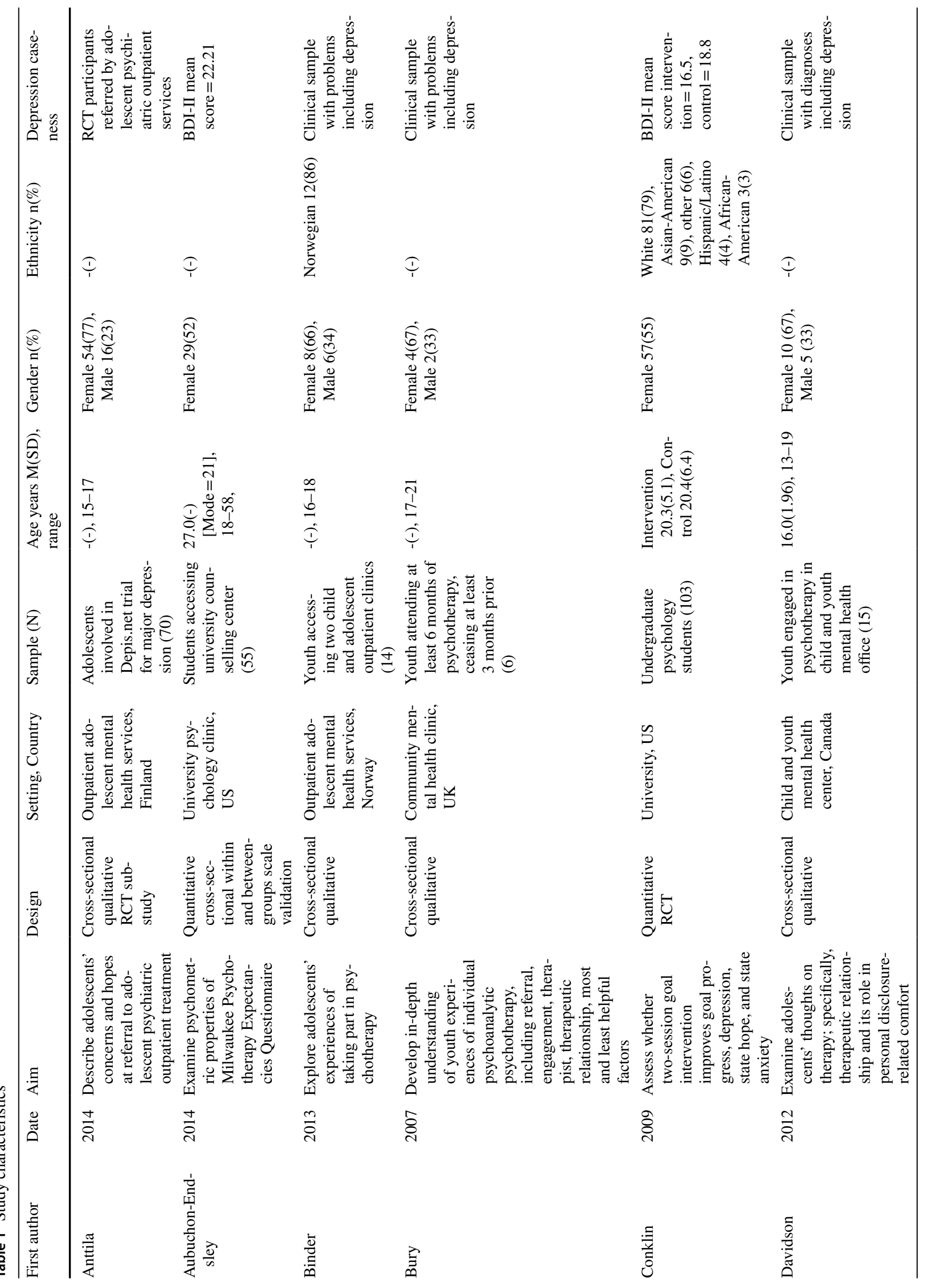




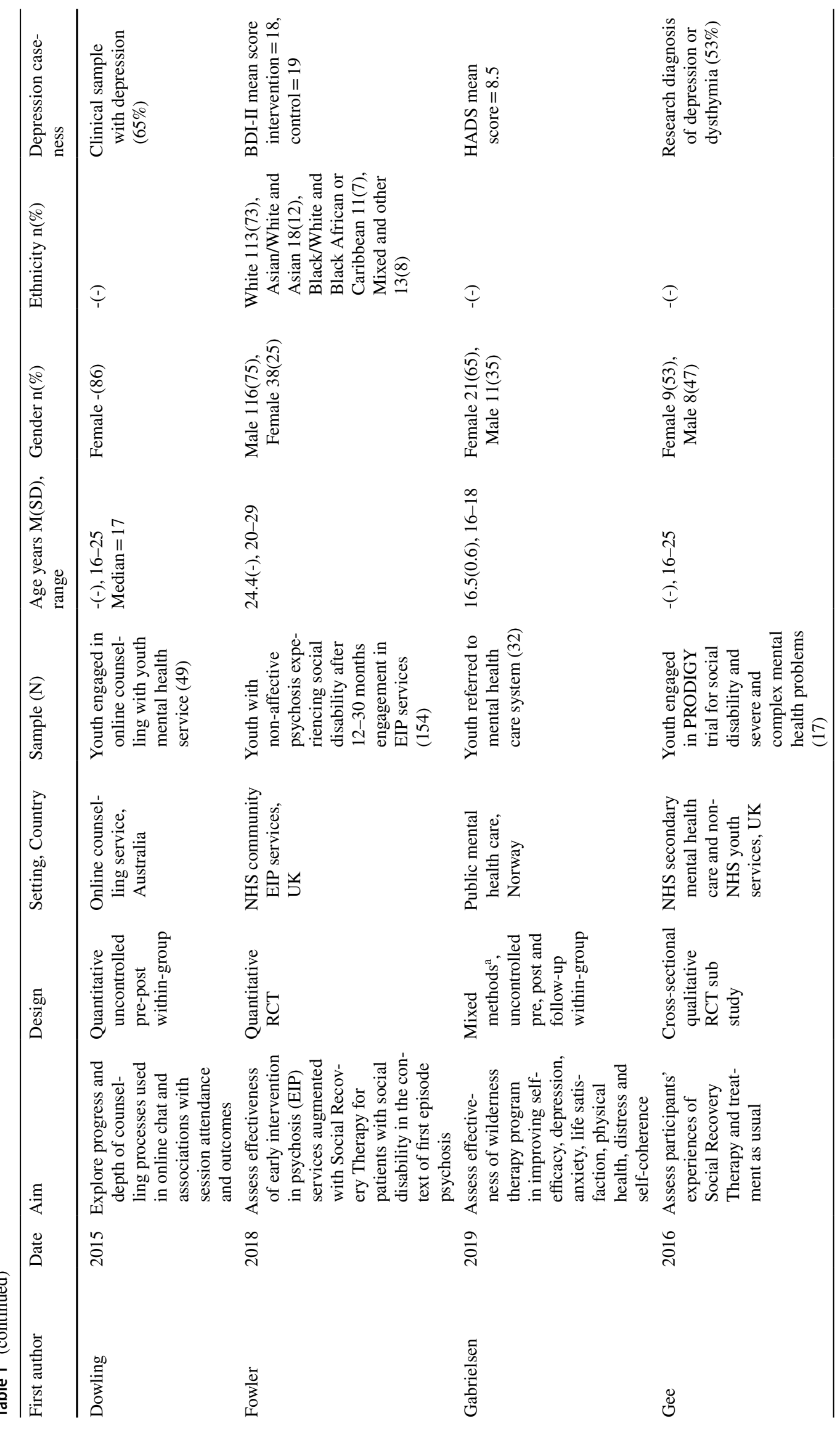




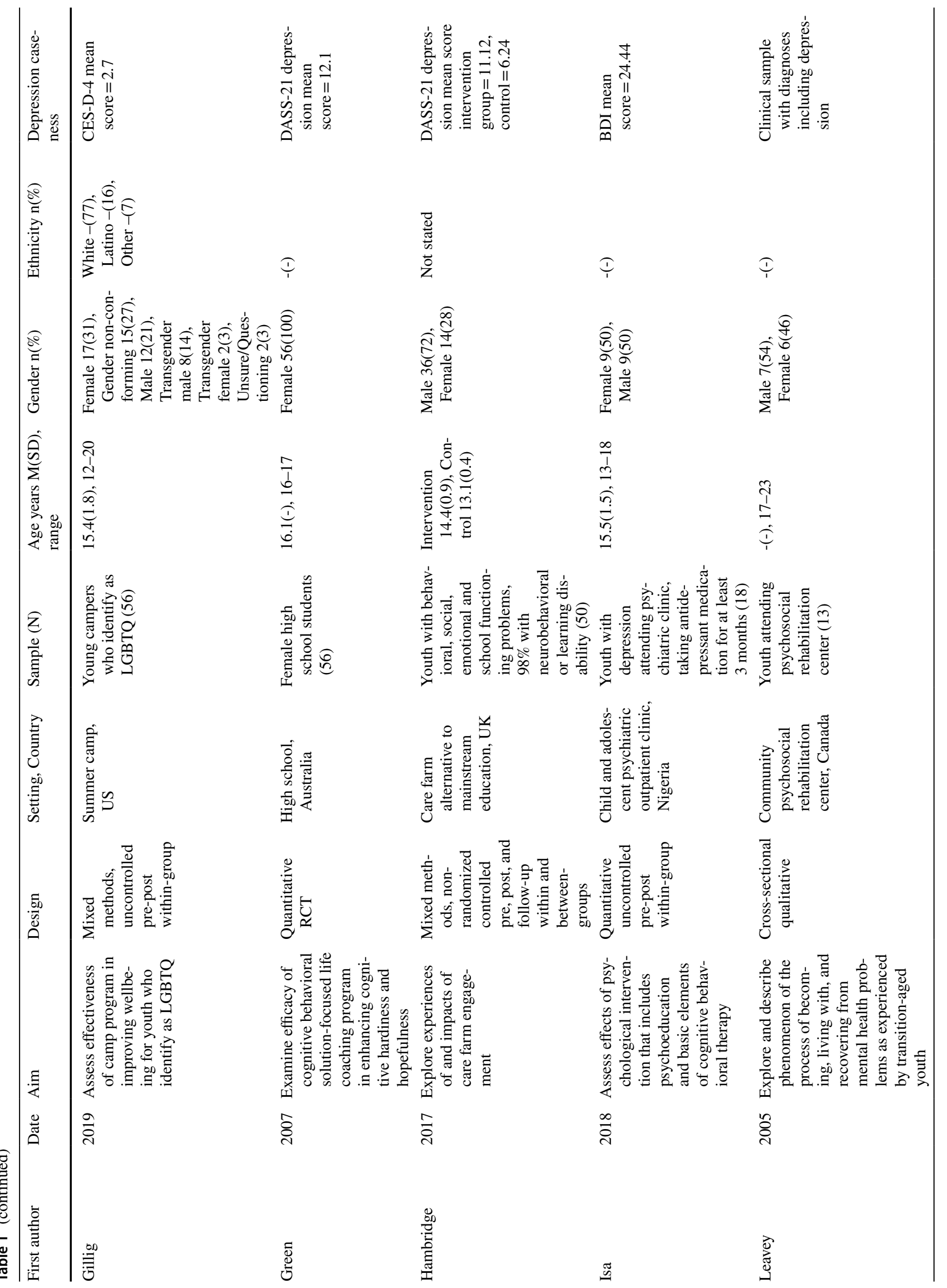




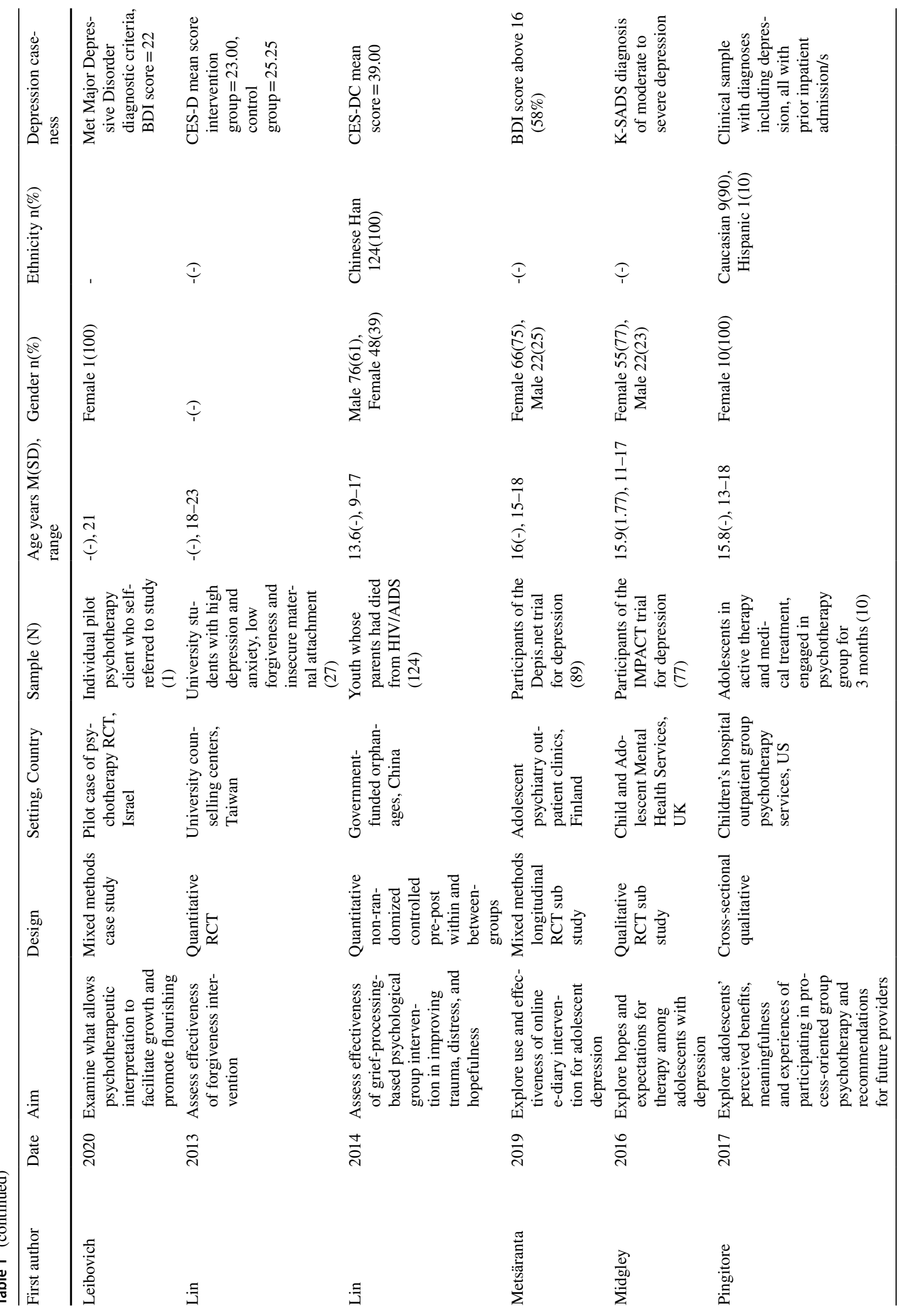




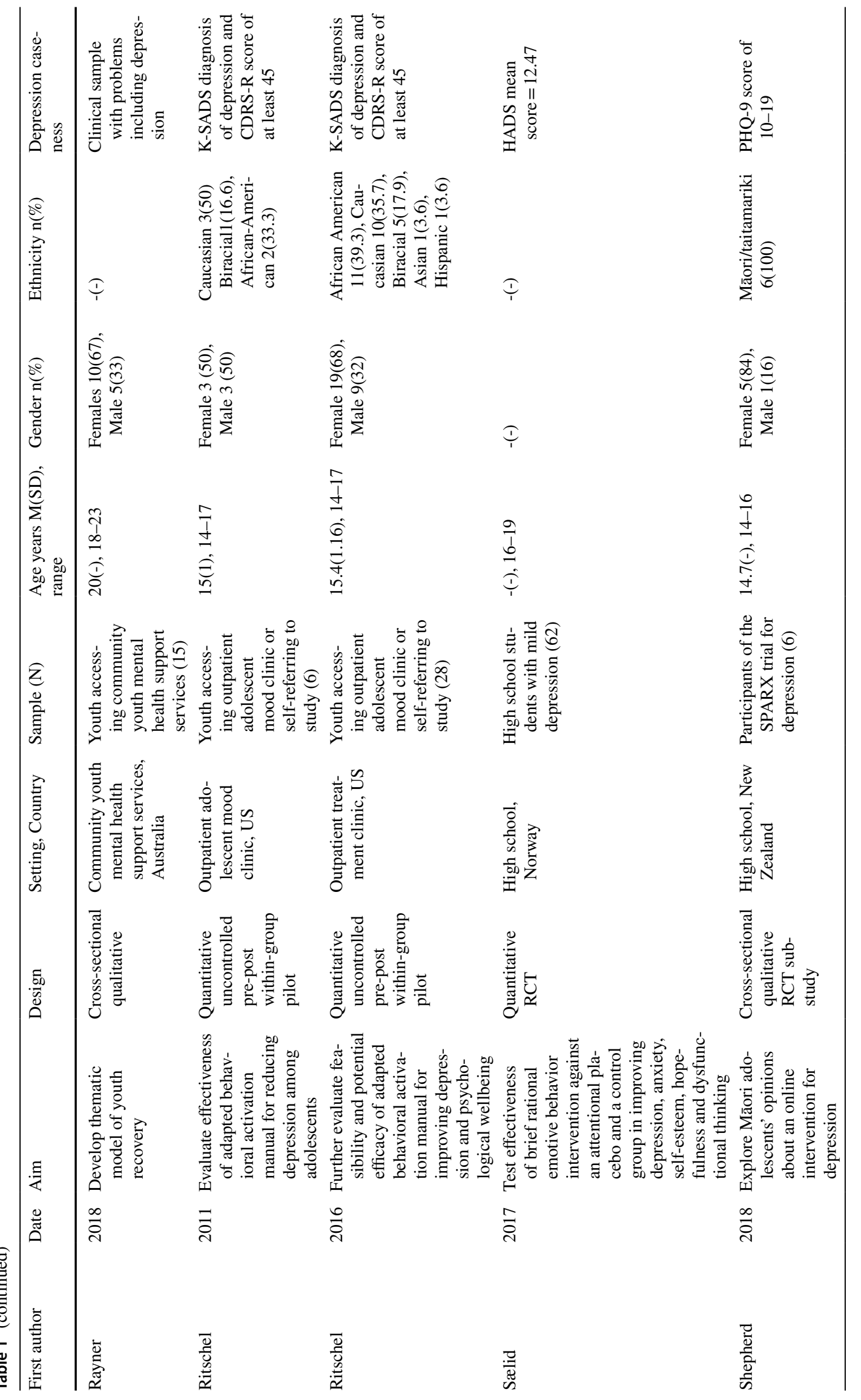




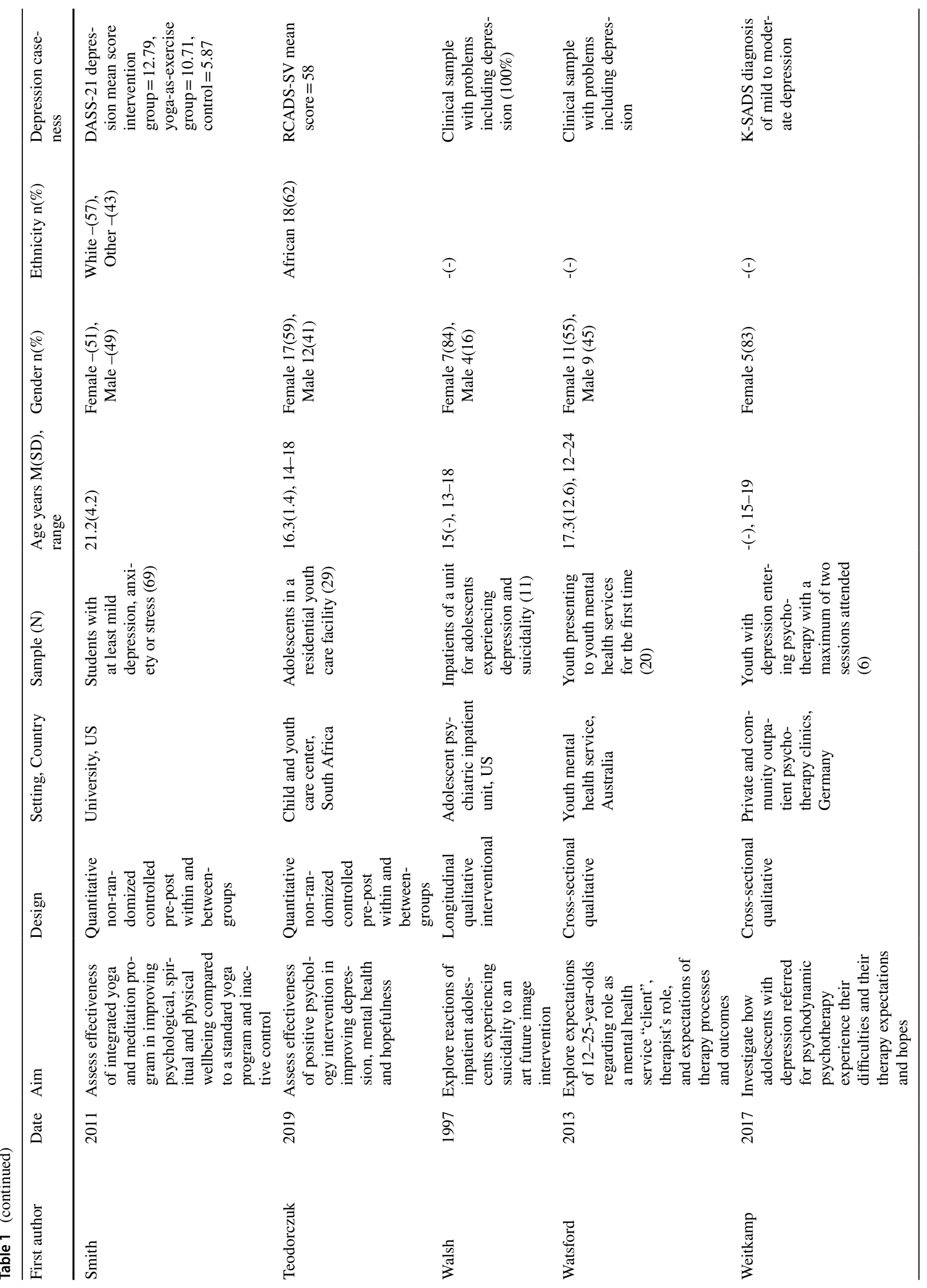




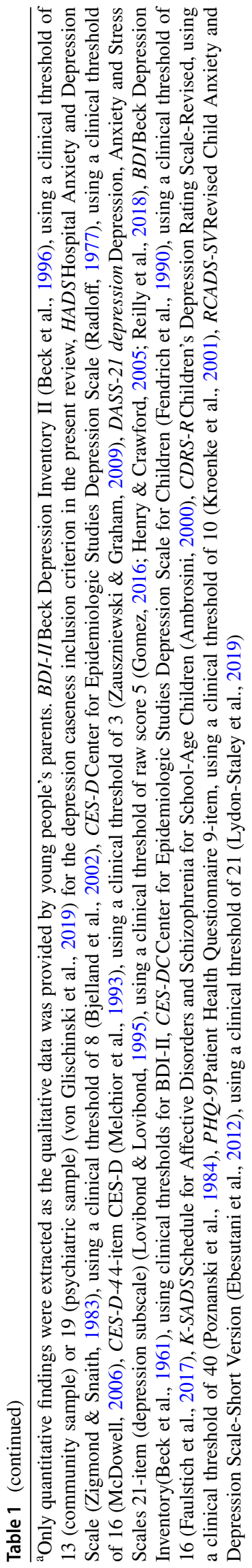

et al., 2019) or mixed populations (Gee et al., 2018; Ritschel et al., 2011, 2016). There was an equivalent mixture of individual and group interventions (Online Appendix E). All but one (Shepherd et al., 2018) intervention were provided in person, mostly by mental health professionals.

Nearly all randomized or controlled studies reported significant between-group effects with respect to significantly increasing hopefulness and reducing depression pre- and post-intervention (Fowler et al., 2018; Green et al., 2007; Sælid \& Nordahl, 2017; Smith et al., 2011), showing mainly moderate to large effects of Social Recovery Therapy (SRT), life coaching, and yoga and meditation (not yoga as exercise (Smith et al., 2011)) on these outcomes. Similarly, most uncontrolled studies reported significant within-group effects in increasing hopefulness and reducing depression (Gillig et al., 2019; Isa et al., 2018; Ritschel et al., 2011), showing mainly moderate to large effects of behavioral activation, psychoeducation and CBT, and an LGBTQ camping intervention on these outcomes. Only a positive psychology group intervention, versus a waitlist control, produced no between or within-group effects on hopefulness or depression (Teodorczuk et al., 2019). All other studies reporting no between-group differences (Conklin, 2009; Lin et al., 2013, 2014; Sælid \& Nordahl, 2017; Teodorczuk et al., 2019) showed within-group increases in hopefulness in both interventions and comparators; the latter including attentional placebo (Sælid \& Nordahl, 2017), goal-visualization (Conklin, 2009), social communication and perspectivetaking (Lin et al., 2013), and an inactive control (Lin et al., 2014). Notably, effect sizes for hopefulness appeared greater for Rational Emotive Behavior Therapy versus its attentional placebo (Sælid \& Nordahl, 2017) and for the grief-based intervention versus its inactive control (Lin et al., 2014). Two studies reported significant improvements in depression for interventions and active controls, with no evident between-group differences (Lin et al., 2013; Sælid \& Nordahl, 2017). Studies which did not measure hopefulness (Gabrielsen et al., 2019; Hambridge, 2017; Shepherd et al., 2018; Walsh \& Minor-Schork, 1997) provided qualitative evidence (Online Appendix F) that it was enhanced by the intervention.

Few studies measured social recovery outcomes (Table 2). One RCT (Fowler et al., 2018) captured time use, finding that SRT led to large and significant gains in time spent in structured activity at 9 months, with some evidence of gains too at 15 months once adjusted for missing data (Fowler et al., 2018). All other studies focused on more subjective self-rated social outcomes such as life satisfaction, with two studies reporting small to medium interventional effects (Gabrielsen et al., 2019; Hambridge, 2017). Qualitative studies provided some evidence for interventional benefits on social recovery (Gabrielsen et al., 2019; Gee et al., 2018; Walsh \& Minor-Schork, 1997). 


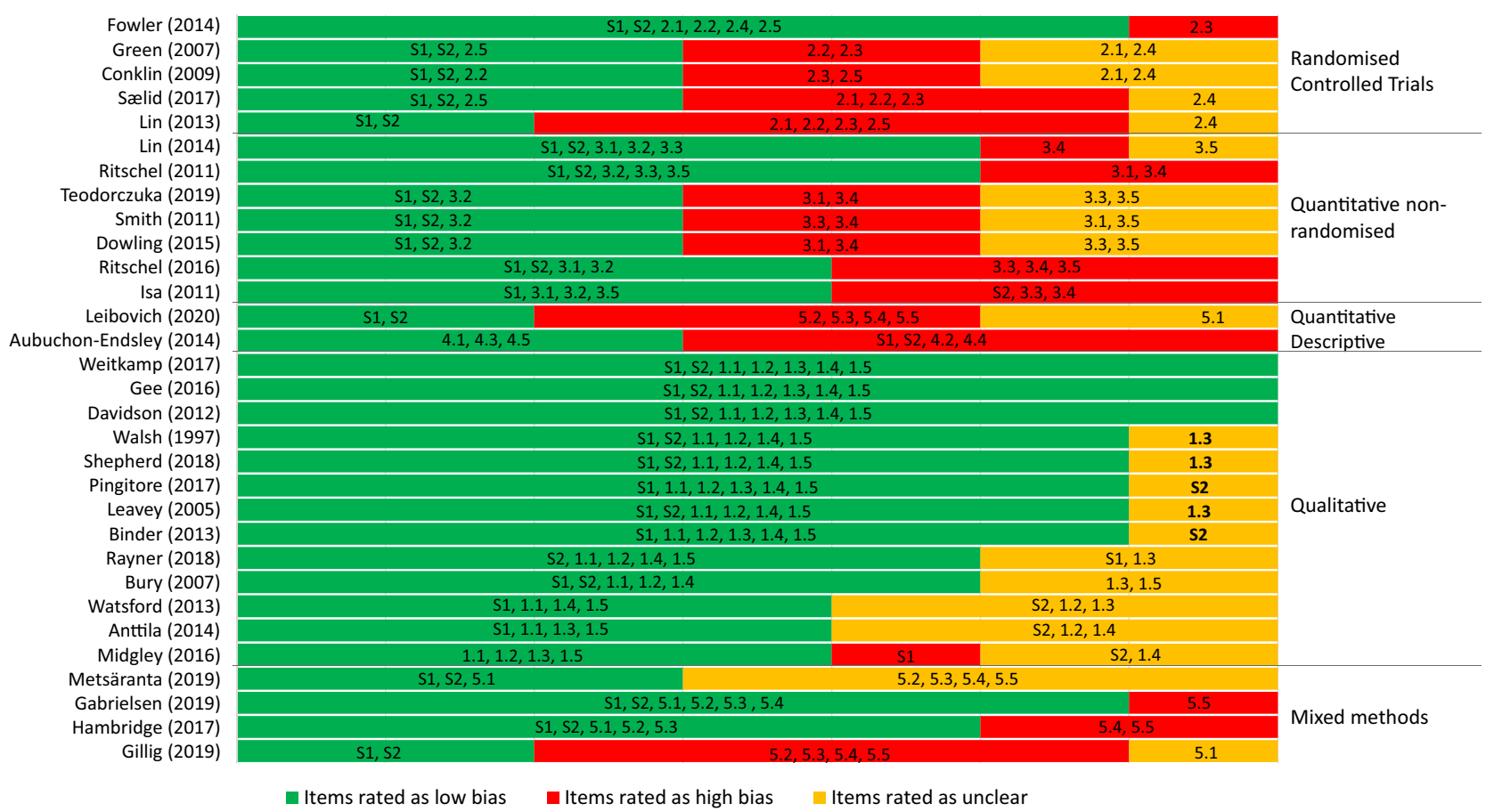

Fig. 2 Risk of bias within individual studies. Notes: See supplementary figure note (Online Appendix D) for corresponding appraisal checklist items. For the purposes of quality appraisal, quantitative descriptive items were used for Leibovich et al. (2020). Whilst the case study is essentially mixed methods, for it presents both numerical and qualitative data with some integration, it is a case study and

Standard Mental Health Care Eight studies presented qualitative (see Online Appendix F) experiences of standard mental health care in the UK (Bury et al., 2007; Gee et al., 2018), Canada (Davidson, 2008; Leavey, 2005), Australia (Rayner et al., 2018), USA (Davidson, 2008), Norway (Binder et al., 2013) and Germany (Weitkamp et al., 2017). Four studies focused on a single intervention or psychotherapy (Binder et al., 2013; Bury et al., 2007; Davidson, 2008; Weitkamp et al., 2017) and three on any previous service experiences (Gee et al., 2018; Leavey, 2005; Rayner et al., 2018). Positive therapeutic relationships, described by one participant as a "bond of hope", were described as providing motivation, inspiration and as catalyzing positive change (Davidson, 2008). It was important that the professional was hopeful, both wanting positive outcomes for the young person and believing in their likely occurrence (Davidson, 2008). Experience of "venting" in early therapy mobilized hopefulness and positive expectancies of functional improvement (Davidson, 2008). Therapist assessment, when performed competently and with relational authenticity, enhanced hopefulness through connection with the young person's uniqueness and strengths, whilst also bringing order to the felt sense of chaos and hopelessness (Binder et al., 2013). Using standardized assessment tools was validating and qualitative data were presented to illustrate quantitative ratings rather than providing any qualitative analysis. It was noted in addition that participation in the art future image intervention in the study conducted on an adolescent psychiatric inpatient unit (Walsh \& MinorSchork, 1997), could not be considered completely voluntary and this may have influenced participants' responses

normalizing; providing hopefulness that the existence of standardized frameworks to capture problem experiences might be indicative of the existence of solutions (Binder et al., 2013). Conversely, participants in one study experienced UK youth mental health service provision as too limited, but some suggested this encouraged them to exert selfagency in their recovery (Gee et al., 2018).

One study quantitatively assessed experiences of an online counselling service (Dowling \& Rickwood, 2015) (Table 2). There was no significant effect of one or two sessions on hopefulness, irrespective of observed session progress or depth, although there was a significant reduction in psychological distress (Dowling \& Rickwood, 2015). Similarly, in the trial of Social Recovery Therapy (Table 2), standard Early Intervention in Psychosis services led to reductions in depression, but no significant gains in hopefulness (Fowler et al., 2018). The lived experience panel emphasized that mental health services can enhance hopefulness. However, the panel described services as focusing too little on hopefulness and that it should be considered a "first resort". 


\section{In What Settings and Contexts, and For Whom, Does Hopefulness Appear Most Important and Effective (Research Question 2)?}

There was no clear evidence of hopefulness being differentially important or beneficial in different contexts. Effect sizes did not seem to observably differ consistently according to study sample (e.g. size, age, gender, population, baseline hopefulness or depression severity) or intervention characteristics (e.g. type, duration, session number, or mode). Qualitative studies positioned hopefulness as generally important to recovery in depression, saying that hopefulness is important to hopeless people (Walsh \& Minor-Schork, 1997). For adolescents aged around 18 years, impending adulthood appeared to provide motivation to engage in psychotherapy (Gee et al., 2018); yet studies did not indicate lesser importance or effects related to hopefulness at other ages. One study suggested that imagining the best possible future self can be challenging or perceived negatively (Teodorczuk et al., 2019). Another study found a significantly greater degree of self-reported goal completion and significantly smaller reduction in depression for people who had greater baseline trait hopefulness; but only in the active goalskills intervention and not the goal-visualization control (Conklin, 2009). Therefore, goal-skills interventions may better enhance hopefulness for hopeful people but have less impact on depression.

The lived experience panel agreed that whilst hopefulness is important to all youth with depression, it is not necessarily unilaterally beneficial. In general, identified challenges to hopefulness included difficulties in feeling agentic and the sense that repeated failures to achieve goals may erode hopefulness over time. Some youth spoke of hopefulness becoming salient during adversity, rather than being an underlying or continuous presence. With respect to specific barriers, it was suggested that locating and enacting hopefulness is arguably more challenging for people with severe or long-lasting depression and in the context of additional intersecting challenges (Online Appendix G); "people who need hopefulness tend to be faced with actions that bar them from hope".

\section{What are the Putative Processes and Mechanisms by Which Hopefulness Impacts on Outcomes (Research Question 3)?}

Where Hopefulness Comes from and What Youth with Depression Hope For Five qualitative (Anttila et al., 2015; Bury et al., 2007; Midgley et al., 2016; Watsford et al., 2013; Weitkamp et al., 2017) and one quantitative (Aubuchon-Endsley \& Callahan, 2014) study focused on hopes or expectancies for intervention or outcome. Two studies related to a trialed novel intervention (Anttila et al., 2015; Midgley et al., 2016) and four to standard psychotherapy
(Aubuchon-Endsley \& Callahan, 2014; Bury et al., 2007; Weitkamp et al., 2017) or mental health care more generally (Watsford et al., 2013). Three studies captured hopes at intervention outset (Anttila et al., 2015; Midgley et al., 2016; Watsford et al., 2013) and three involved a more current or retrospective focus (Aubuchon-Endsley \& Callahan, 2014; Bury et al., 2007; Weitkamp et al., 2017). Hopedfor changes appeared typical and normative, including increased self-understanding, independence, better coping, greater interpersonal relationship quality and quantity, positive engagement and performance in meaningful occupational and vocational activities (Anttila et al., 2015; Midgley et al., 2016; Weitkamp et al., 2017). Psychological hopes, e.g. greater self-understanding, were positioned as the foundation for and route to achieving positive social recovery outcomes such as better school performance (Midgley et al., 2016; Rayner et al., 2018). Youth's hopes for their therapist echoed the qualities experienced as hope-enhancing in other studies; competent, experienced, professional, understanding, caring and nice (Midgley et al., 2016; Weitkamp et al., 2017).

Studies suggested that hopefulness was self-reinforcing in that the initial development of hopefulness within an intervention appeared to act as a primer for a chain of events in which youth became aware that the ongoing effortful pursuit of goals (Gabrielsen et al., 2019; Gee et al., 2018; Hambridge, 2017; Metsäranta et al., 2019). The associated observable small gains made further increased their hopefulness and provided motivation to pursue more ambitious goals (Gabrielsen et al., 2019; Gee et al., 2018; Hambridge, 2017; Metsäranta et al., 2019). A few studies considered how interventional components influenced hopefulness. Qualitative studies suggested that engaging in help-seeking itself built self-efficacy and resilience (Rayner et al., 2018), having a computer character personifying hope generated hopefulness (Shepherd et al., 2018), visually depicting one's future self-image provided a "springboard" into actively expecting and planning for a positive future (Walsh \& Minor-Schork, 1997), and that CBT techniques formed "building blocks" from which youth could use their increased self-agency to pursue meaningful goals (Gee et al., 2018). One quantitative study found that greater self-reported goal progress during the intervention predicted greater increase in hopefulness from post-intervention to one-week follow-up (Conklin, 2009).

Other studies focused on the relational enhancement of hopefulness. One study predicted that a LGBTQ camping intervention increased hopefulness through campers' aspirational identification with camp counsellors and other campers, and associated positive identity formation and empowerment (Gillig et al., 2019); however this model was not empirically supported. However, individual hopefulnessenhancing interventions appeared predicated on a positive 


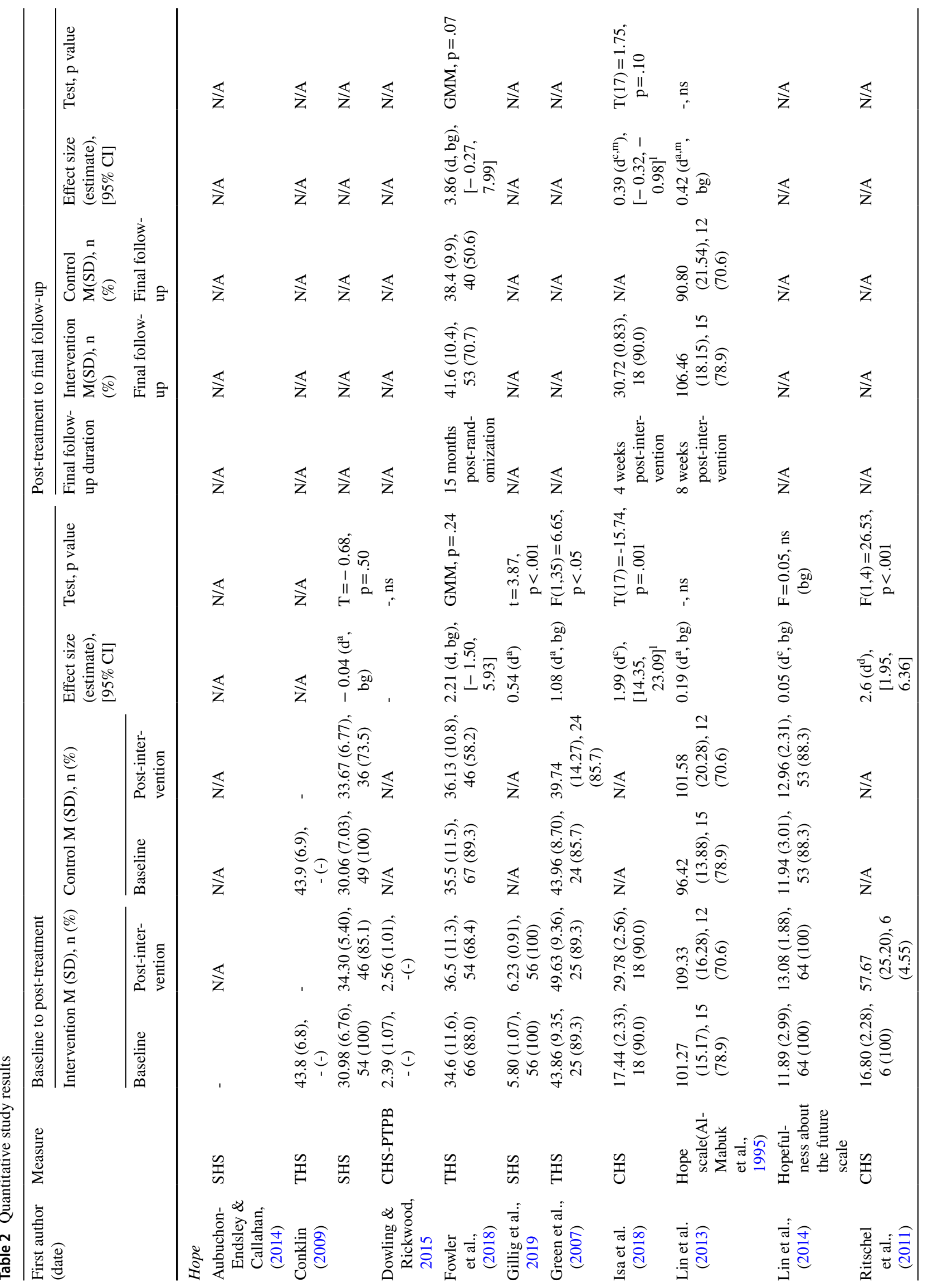




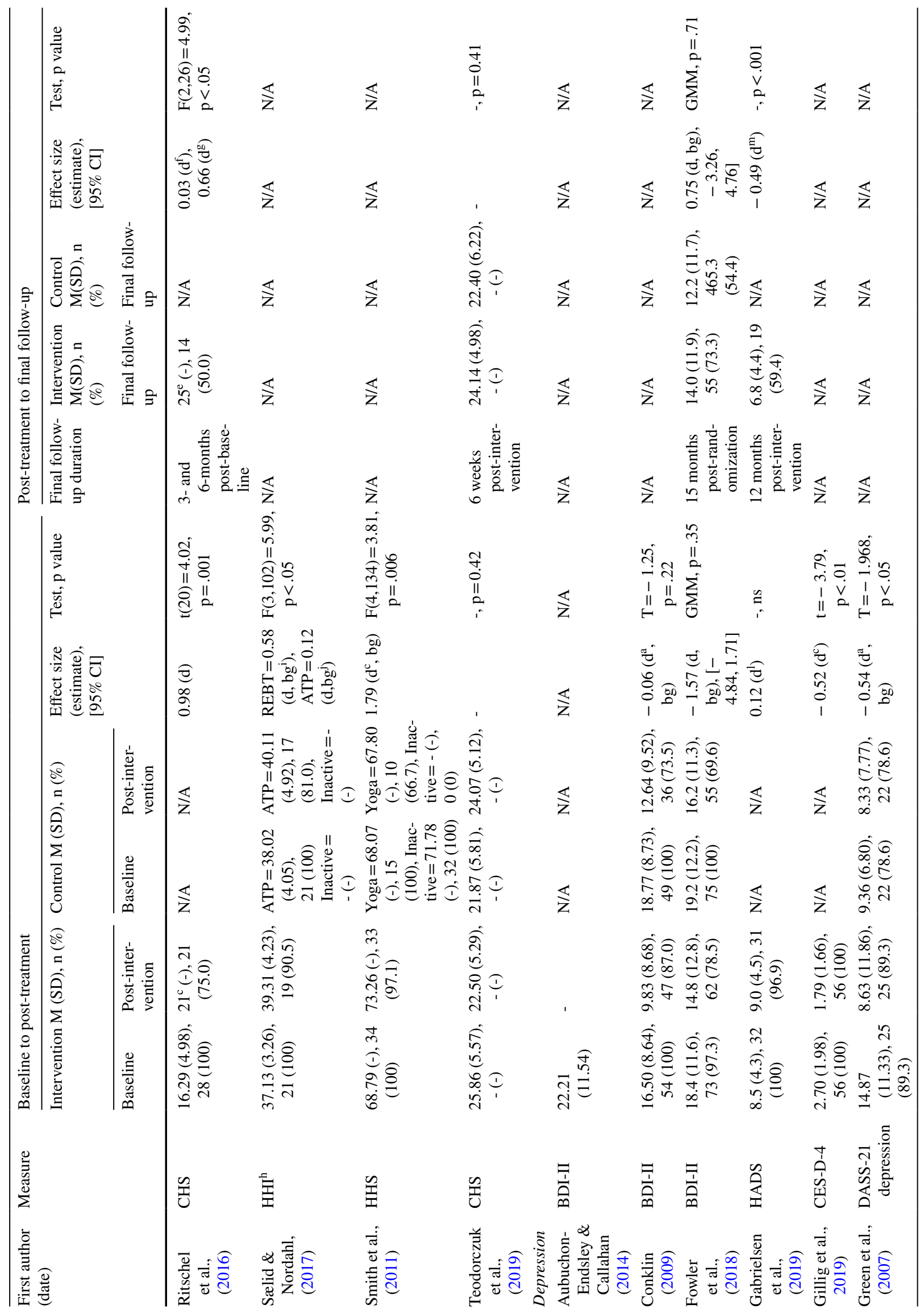




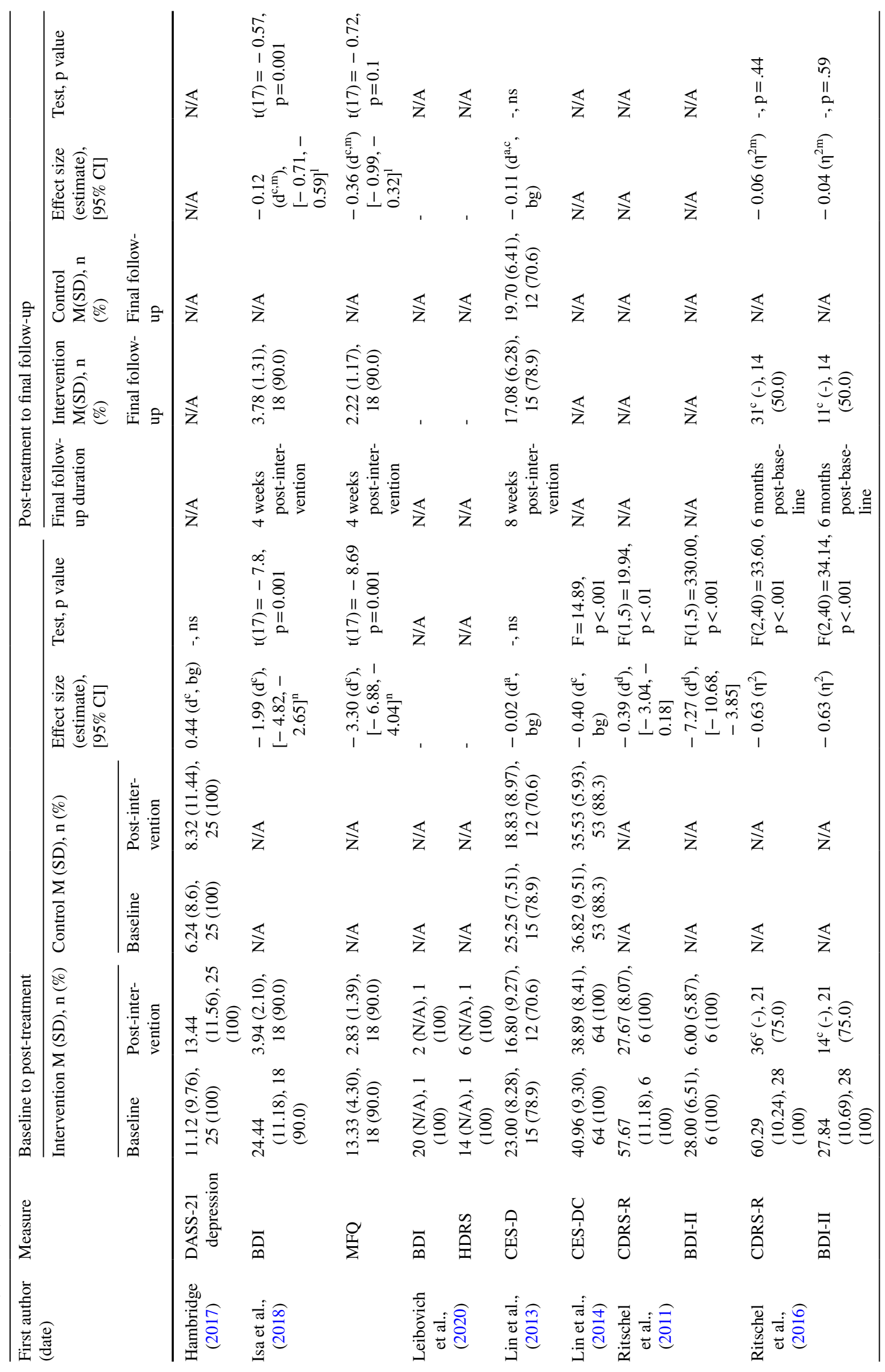




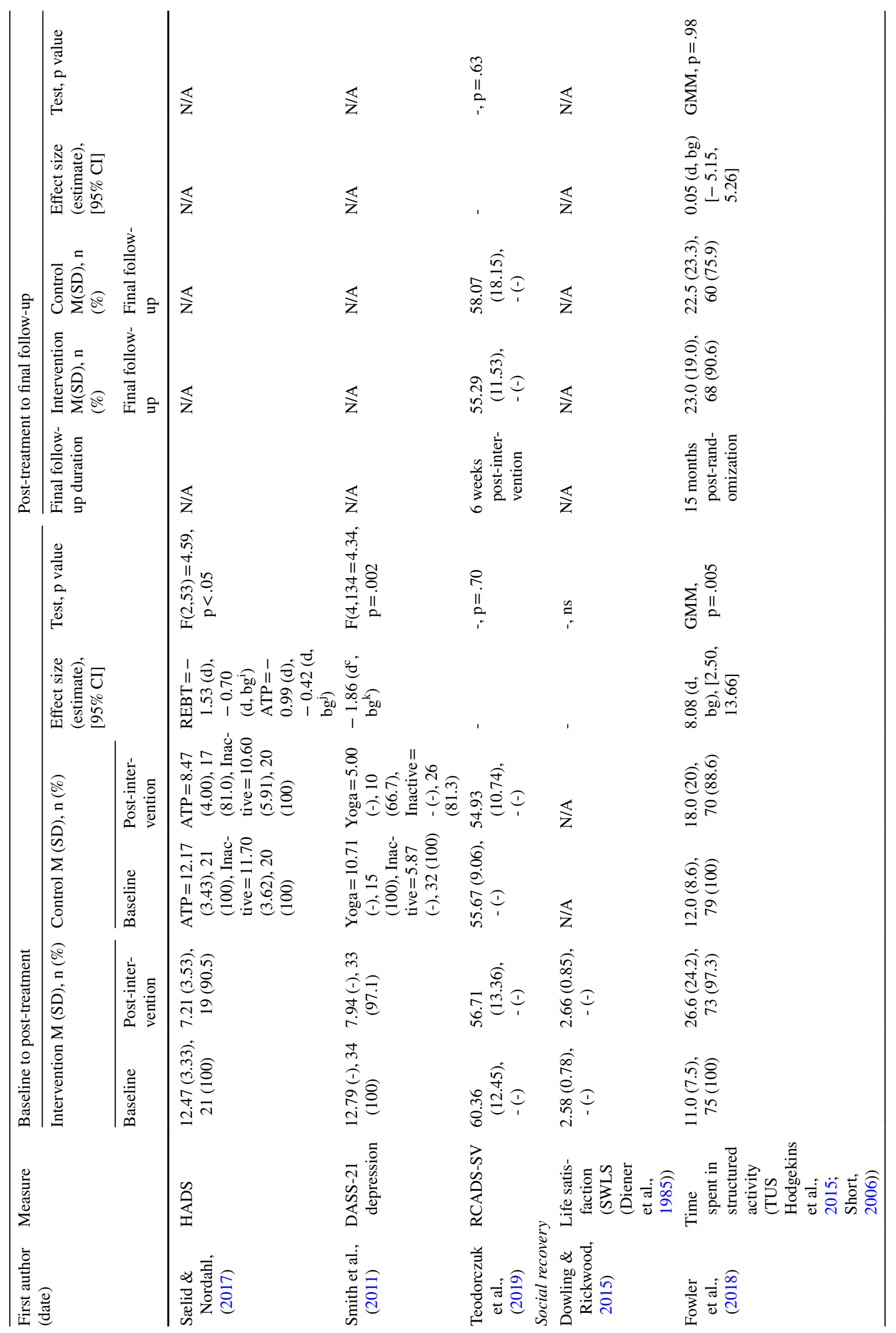




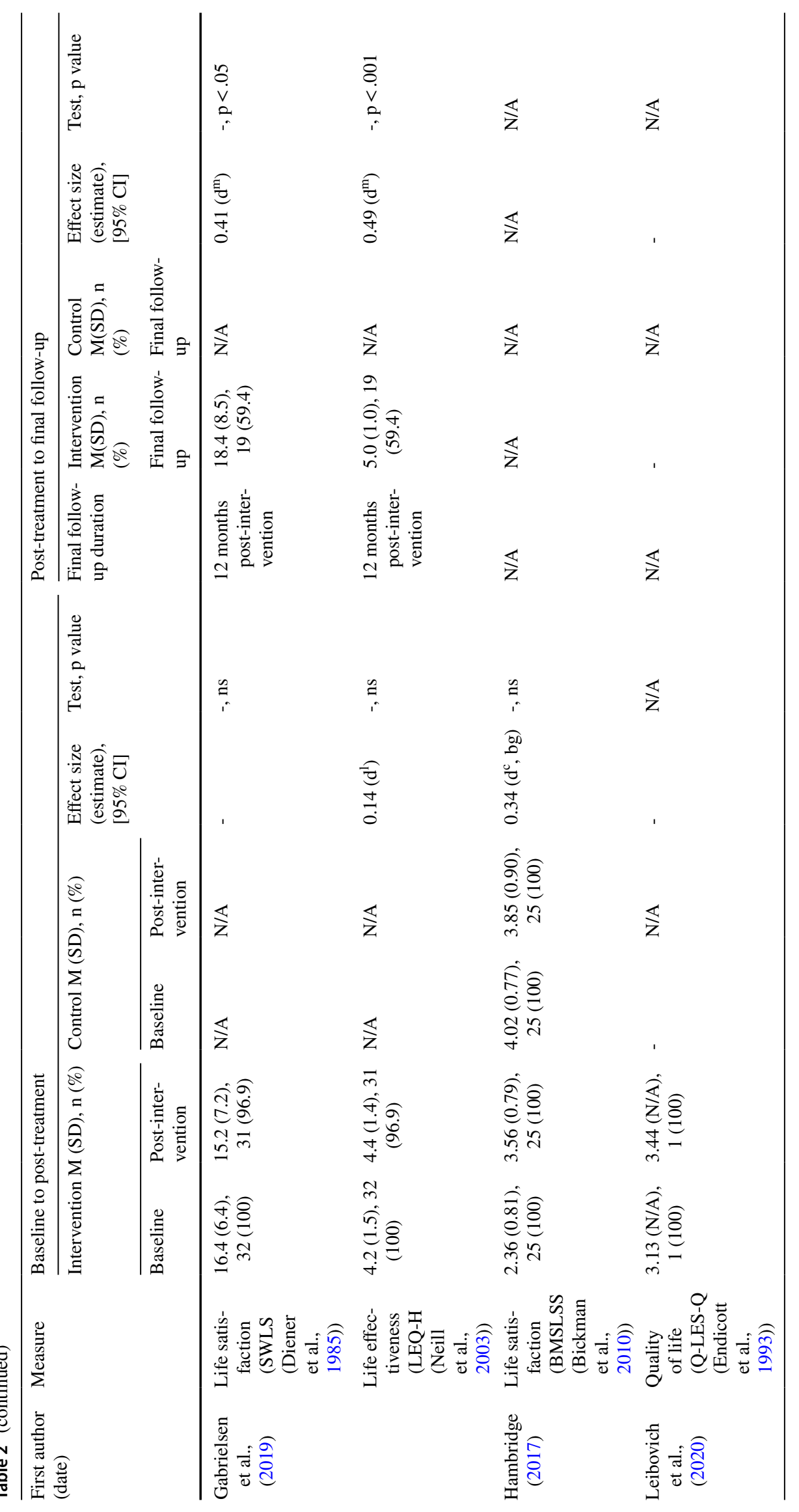




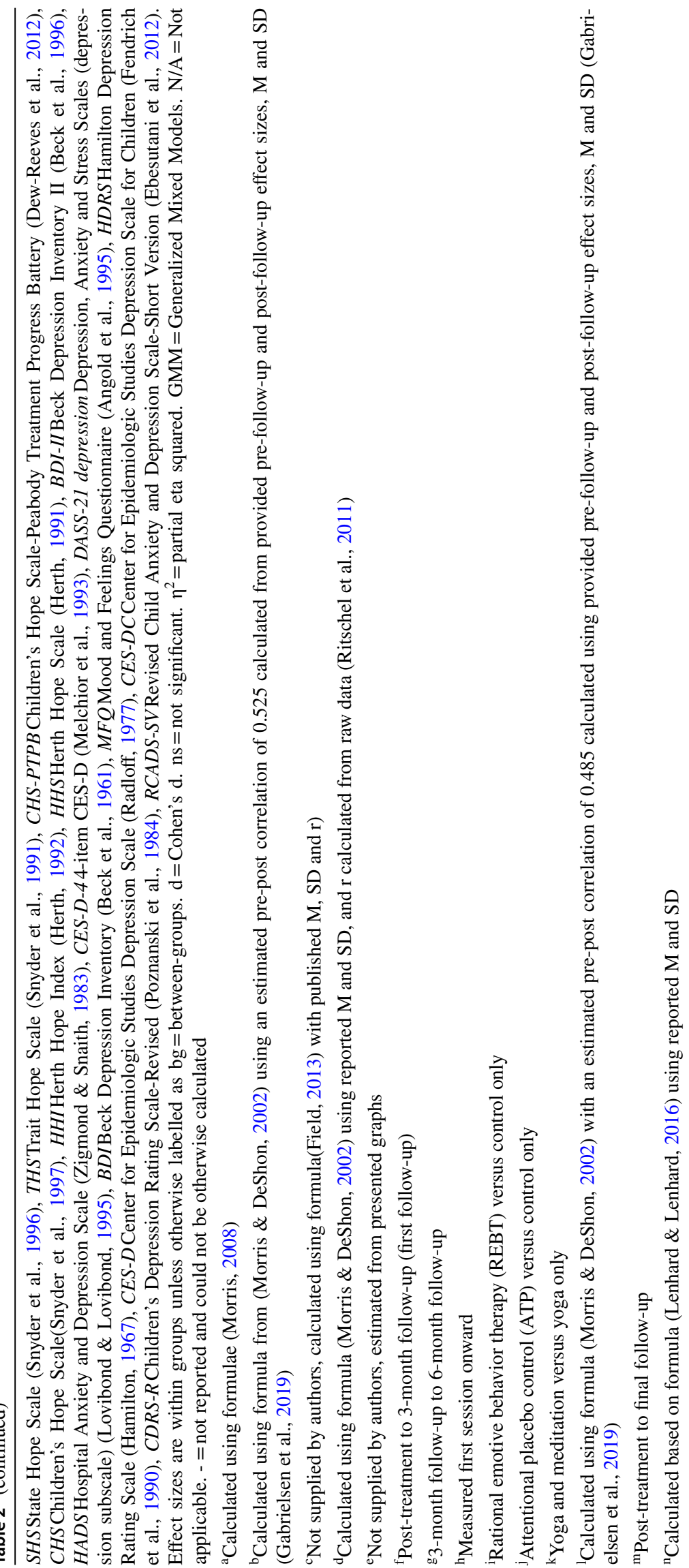


therapeutic relationship. Such relationships needed to be with professionals who held hopefulness for and cultivated it in youth (Davidson, 2008; Gee et al., 2018; Hambridge, 2017), through providing support (Rayner et al., 2018) and unconditional positive regard (Davidson, 2008; Hambridge, 2017), offering interpretations suggestive of potential for change (Leibovich et al., 2020), focusing on collaboratively identified meaningful goals (Gee et al., 2018), modelling and supporting the process of breaking down goals into small steps (Hambridge, 2017), finding solutions to barriers (Hambridge, 2017), helping youth achieve specific goals (Hambridge, 2017; Rayner et al., 2018), and continuing to embody hopefulness despite any setbacks (Davidson, 2008). One study participant emphasized that hopefulness arises from the therapist seeming strong and stable, for this communicates that problems are bearable and can be overcome (Weitkamp et al., 2017). Studies of specific psychological therapies and standard mental health care both suggested a benefit to 'groupiness' (Leavey, 2005; Pingitore \& Ferszt, 2017; Walsh \& Minor-Schork, 1997), with a psychotherapy group being termed a "gathering of hope" (Pingitore \& Ferszt, 2017). Group benefits appear to hinge on common experience, collective agency and a shared goal of recovery (Leavey, 2005; Pingitore \& Ferszt, 2017), discussing the future with other youth (Walsh \& Minor-Schork, 1997), and enacting hopefulness through helping and supporting other group members (Pingitore \& Ferszt, 2017).

Finally, whilst some youth described hopeful thinking as an intrinsic or adopted attitude (Gee et al., 2018; Leavey, 2005), other studies suggested its development is gradual. Two novel intervention trials found no post-intervention increase in hopefulness, but observed significant gains at 12 (Gabrielsen et al., 2019) and 15-month follow-up (Fowler et al., 2018). Another study found significant gains in hopefulness from 3 to 6-month follow-up (Ritschel et al., 2016). This pattern was not evident for depression, as follow-up effect sizes were observably smaller than at post-intervention (Table 2). Qualitative studies echoed a pattern of delayed increase in hopefulness. Hopefulness could be completely absent for youth at intervention outset (Hambridge, 2017), in the context of depression involving diminished ambition and interest in life (Anttila et al., 2015; Metsäranta et al., 2019; Walsh \& Minor-Schork, 1997) and compounded by others' low expectations for the young person's future (Hambridge, 2017). Youth stated that interventions need to be long-term (Gabrielsen et al., 2019; Gee et al., 2018), for meaningful changes would take months or potentially years to be noticeable (Gabrielsen et al., 2019). Thus, hopefulness may need to be gradually built through an evolving sense of therapeutic gains (Hambridge, 2017; Metsäranta et al., 2019) within a supportive and encouraging interpersonal environment
(Hambridge, 2017). Hopefulness gained during intervention can then function as a primer and motivator for ongoing and increasingly effortful goal pursuit post-intervention (Gabrielsen et al., 2019; Gee et al., 2018; Hambridge, 2017).

The lived experience panel described hopefulness as unique and individual with respect to its sources, nature, and effects, stating it "will never be one size fits all". The panel agreed that positive therapeutic relationships between professionals and youth are necessary for scaffolding hopefulness. The group emphasized that mental health professionals should not be too "explicit" or directive in discussing or encouraging hopefulness; "[t]herapists should work to find what uniquely brings their patient hope, rather than trying to be prescriptive about it". The panel advised professionals to try and implicitly "trigger" hopeful thinking through providing validation, empathy and authenticity, forming meaningful connection with youth's unique hopefulness, using sensitivity and gentleness, providing support to identify meaningful current and short-term goals, and helping to break down goals into smaller parts (see Table 3).

Putative Mechanisms of the Impact of Hopefulness Evidence regarding mechanisms of hopefulness was very limited. Two quantitative studies reported associations between pre-treatment hopefulness or expectancies and engagement (Aubuchon-Endsley \& Callahan, 2014; Ritschel et al., 2016); with greater hopefulness predicting the likelihood of completing behavioral activation (Ritschel et al., 2016), but more positive treatment expectancies predicting reduced university counselling attendance (AubuchonEndsley \& Callahan, 2014). The latter study found no correlation between hopefulness and treatment expectancies (Aubuchon-Endsley \& Callahan, 2014), however, suggesting these may reflect different phenomena. Two quantitative studies considered mechanisms the impact of hopefulness. One found a concurrent association between increased state hopefulness and reduced depression (Conklin, 2009) and the other hypothesized, but did not find, that the baseline level and gains in hopefulness would moderate the reduction in depression (Gillig et al., 2019). Multiple putative candidates, however, for how hopefulness impacts further outcomes were identified by lived experience experts. Their reported observations were that hopefulness facilitates support-seeking, improves mood and negative thinking, protects against relapse and suicidality, and motivates goal-directed action. Research evidence and lived experience identified potential mechanisms were combined into a preliminary hopefulness process model (Fig. 3), which suggests an ultimately self-reinforcing impact of hopefulness through increasing treatment engagement, clinical and functional improvements, and ongoing goal pursuit. 
Table 3 Youth lived experience panel quotes about how mental health professionals can enhance hopefulness

\begin{tabular}{|c|c|}
\hline Component & Illustrative quotation \\
\hline Validation, empathy and authenticity & $\begin{array}{l}\text { "I've had experiences where therapists and people in mental health mentoring } \\
\text { roles have encouraged me to try and feel hope about situations that are genu- } \\
\text { inely extremely negative. It can make me feel like I haven't been listened to, } \\
\text { like they haven't understood the extent of the situation, or like they're trying } \\
\text { to put a plaster over some glaring societal issues which are linked to probably } \\
\text { the majority of mental health issues in the population." }\end{array}$ \\
\hline Connect with unique hopefulness & $\begin{array}{l}\text { "Sitting down with young people getting to know them and supporting them in } \\
\text { their own unique ways of finding hope." }\end{array}$ \\
\hline Sensitive and gentle triggering of hopeful thinking processes & $\begin{array}{l}\text { “...mental health professionals [should] not be too explicit during therapy etc. } \\
\text { about hopefulness as I think this could potentially make people feel worse if } \\
\text { they can't think of anything they feel hopeful about, but instead if the profes- } \\
\text { sionals address it in a non-direct [way], they are more likely to get some } \\
\text { answers out of people as to what they feel hopeful about without the person } \\
\text { even realizing it, then they can build on helping the person to recognize that } \\
\text { this is there thing(s) to be hopeful about.” } \\
\text { "...being told you need to have hope doesn't help. If you're feeling depressed } \\
\text { maybe you don't feel like you have many good things in life. But triggering the } \\
\text { thought process about what you can have hope for.” }\end{array}$ \\
\hline Support to identify meaningful current and short-term goals & $\begin{array}{l}\text { "I agree that if a [professional] simply identifies things/goals to be hopeful for, } \\
\text { this isn't enough for the [young person], they need to believe in the goals and } \\
\text { need support to achieve them. For a [young person] experiencing low mood/ } \\
\text { depression, they may need goals to focus on in the next days/weeks as longer- } \\
\text { term goals may be overwhelming. For example, if a [professional] suggests } \\
\text { being hopeful about the possibility of future careers and relationships, this } \\
\text { could increase anxiety for some people and could be counterproductive. I } \\
\text { think that it would be more useful to focus on what's important for that indi- } \\
\text { vidual in that point in time." }\end{array}$ \\
\hline Helping to break down goals into smaller parts & $\begin{array}{l}\text { "I think it helps to emphasize the power of small actions. This allows the young } \\
\text { person to trust in the process because often goals can take time to achieve } \\
\text { and they are built on repeating small actions over time. A small action is often } \\
\text { more accessible so the young person can still feel in control." }\end{array}$ \\
\hline
\end{tabular}

\section{Risk of Bias Across Studies}

With respect to the risk of bias at the outcome level, there is moderate certainty in the review conclusions according to GRADE (Oxman, 2004) domains. Publication bias was not estimated. There is a high risk of bias with respect to the variable quality of individual studies. However, there appears to be low inconsistency and indirectness, for almost all interventions appeared to improve hopefulness and reduce depression. All were evaluated within the population of interest whilst simultaneously reflecting diversity in age, gender, ethnicity, geography and setting. Most studies, irrespective of quality, reported moderate to large effect sizes on hopefulness and depression, however, whilst confidence intervals were infrequently reported or calculable, those present suggest low precision. Nonetheless, there is a high level of coherence across quantitative, qualitative, and mixed methods evidence and with the perspectives of young lived experience experts consulted.

\section{Discussion}

Hopefulness is arguably of central importance to the recovery of youth with major or complex youth depression, yet understandings are limited as to how hopefulness can best be enhanced in treatment and how it impacts on symptom and social recovery outcomes. Existing reviews have concluded that hopefulness predicts mental health and positive functioning generally for students (Griggs, 2017) and adolescents (Esteves et al., 2013), yet have not specifically considered evidence for the role and impact of hopefulness for youth with mental health problems. However, hopefulness is especially relevant to depression, which is characterized by negative thoughts and expectations for the future (Bjärehed et al., 2010). Arguably hopefulness may underlie all positive psychotherapeutic change (Taylor, 2000), whether explicitly a focus of therapy or not. Hopefulness is additionally important more broadly in standard mental health 


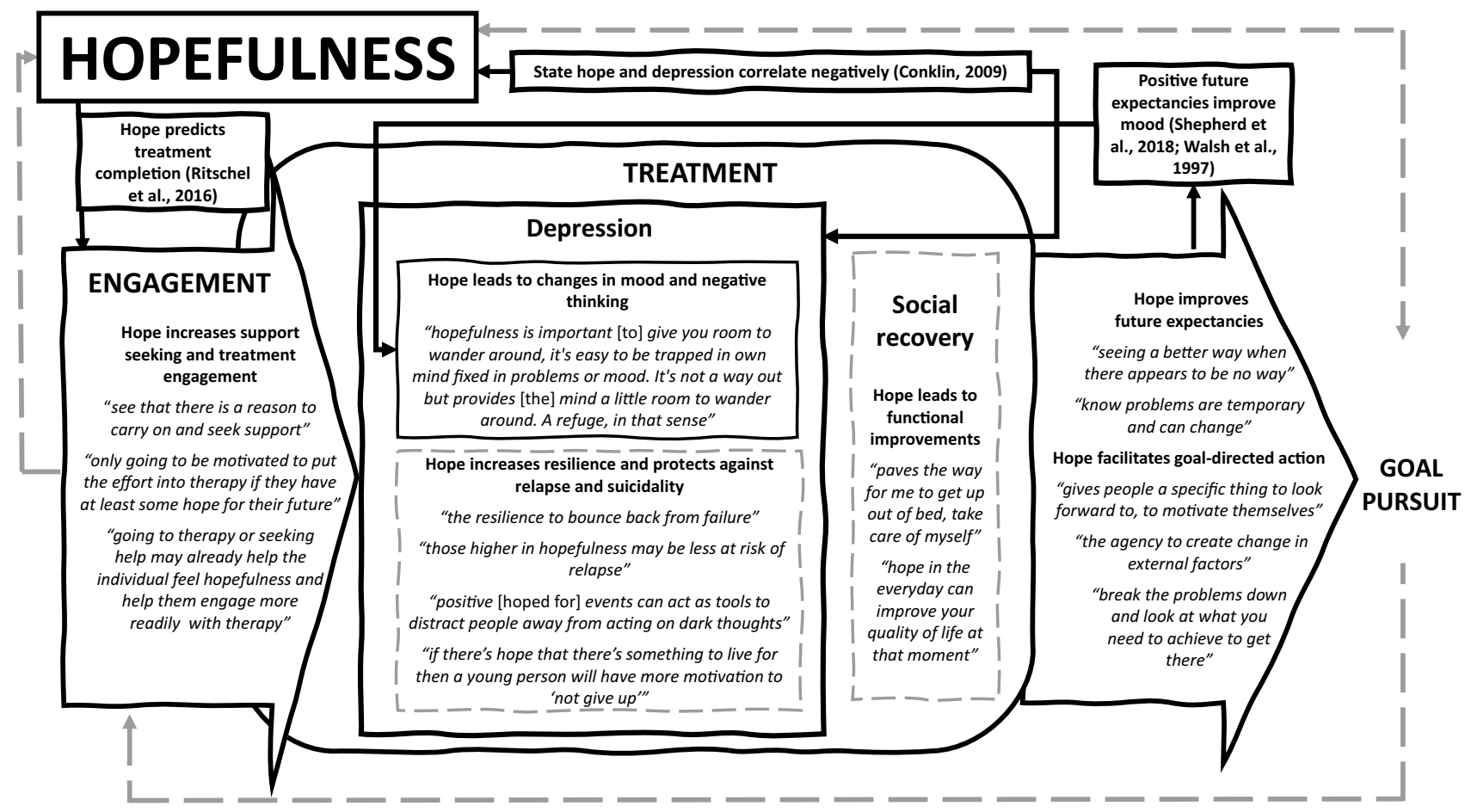

Fig. 3 Preliminary process model of the mechanistic impact of hopefulness on clinical and social recovery outcomes for youth with depression. Notes: Grey dashed lines indicate putative mechanisms identified by lived experience experts (verbatim quotes in italics). Black solid lines indicate putative mechanisms identified in reviewed scientific evidence treatment. Yet limited research has focused on evidence for benefits of hopefulness in these different treatment settings, or considerations of how to best enhance hope and how hope in turn impacts on symptomatic and social recovery. This review synthesized evidence of the development and impact of hopefulness within specific psychological interventions and standard mental health care in youth depression.

The conclusion of this review is that hopefulness is a key active ingredient for youth with major or complex depression. The evidence review suggests that standard mental health care and varied novel CBT-based and alternative talking and activity-based interventions appear able to effectively engender hopefulness and reduce depression. Social Recovery Therapy (Fowler et al., 2018; Gee et al., 2018) and behavioral activation (Ritschel et al., 2011, 2016) reflected higher quality and multiple study evidence and thus maybe be of more reliable benefit. Camping, integrated yoga and meditation, life-coaching and a brief goal-skills intervention additionally appeared effective in enhancing hope and reducing depression (Conklin, 2009; Gabrielsen et al., 2019; Gillig et al., 2019; Green et al., 2007; Smith et al., 2011). Therefore, the most promising specific interventions are those characterized by a clear focus on goals and which use a behavioral therapy or activity-based approach.

In all but one case in which specific psychological therapies failed to significantly increase hopefulness relative to their controls, this was due to increased hopefulness in the control conditions. Therefore, it seems that the simple experience of being heard, for example in an assessment with a competent, warm, hopeful and authentic assessor (Anttila et al., 2015; Binder et al., 2013; Davidson, 2008; Midgley et al., 2016), can be sufficient to start engendering hopefulness in youth depression. Whilst the majority of interventions, including an active listening control (Sælid \& Nordahl, 2017) appeared hope-enhancing, hopefulness did not increase following yoga-as-exercise (Smith et al., 2011) or two online counselling sessions (Dowling \& Rickwood, 2015). Thus, effective hopefulness interventions may need to be imbued with relational intimacy and personal meaning. Similarly in standard mental health care, relational qualities were central to enhancing hopefulness, either in engagement with a competent, caring, relationally authentic professional, or within a group of youth with shared experiences (Binder et al., 2013; Bury et al., 2007; Davidson, 2008).

Notably a brief positive psychology intervention (Teodorczuk et al., 2019) was not associated with improvement in hopefulness or depression. This intervention used a large number of foci and tasks, with two activities reported as unhelpful or even harmful; practicing acts of kindness, which appeared to result in the participant being mocked by others and imagining the positive "future self" which was challenging for a participant. The challenge of imagining the 
"future self" appeared to be related to defensive pessimism, i.e. the self-protective avoidance of positive expectancies; a strategy that similarly appeared evidently in use among youth in two of the reviewed qualitative studies (Hambridge, 2017; Weitkamp et al., 2017). Interventionists must therefore be sensitive to the system around the young person, for it may be hostile and characterized by low support and pessimistic future expectations (Gee et al., 2018; Hambridge, 2017; Teodorczuk et al., 2019).

\section{Limitations}

This review is limited by the fact that study evidence was of variable and often poor quality. As the lower quality studies appeared to report greater effect sizes for reduction in depression, these effects must be taken cautiously. However, study quality has limited bearing on the conclusions about hopefulness. There was no clear relation between quality and effect sizes and lower quality qualitative studies contributed more peripherally; mainly referring to hopes for psychotherapy. The lack of process evaluation, experimental and dismantling approaches in the reviewed research evidence limits somewhat conclusions regarding the best interventions, with what elements, for enhancing hopefulness and how, or what constitutes an adequate treatment "dose". Moreover, this review used a narrative synthesis approach. The limitations of this approach are that effect sizes were compared descriptively, not statistically synthesized. The lack of statistical synthesis, and the inclusion of grey literature, which by its nature involves a more complex, less systematic searching process, may undermine the reproducibility of the current study relative to more traditional systematic reviews (Mahood et al., 2014) and meta-analyses (Campbell et al., 2020).

\section{Strengths}

The current study provides a rich understanding of the enhancement and impact of hopefulness in youth depression. The incorporation of lived experience insights in this review is a key strength of the work. The lived experience panel both contributed to the research team's interpretation of the systematic review and narrative synthesis findings, and generated their own responses to the research questions. The latter in particular contributed unique and valuable insights, especially regarding the processes by which hopefulness can be enhanced, which were not apparent from the published or grey literature as it stands. Such benefits are very much in keeping with those observed in previous participatory style reviews (Harris et al., 2016). Moreover, the inclusivity of the current approach, with respect to synthesizing both scientific and grey literature, and quantitative, qualitative and mixed methods research, broadens the scope of the evidence reviewed (Mahood et al., 2014) and can be considered a strength of this work. The current review did not focus on COVID-19 or its sequelae, and synthesized research was conducted before the global pandemic, yet hopefulness has particular relevance for young people post-pandemic (YoungMinds, 2020); protecting against the mental health impacts of the pandemic (Gallagher et al., 2021) and long periods of social restrictions (Hu et al., 2021). Current findings will have resonance for mental health professionals in effectively supporting young people with their mental health recovery in the post-pandemic context.

\section{Clinical and Research Implications}

The key clinical implications of this review are that hopefulness appears to be an important target for intervention for youth with major or complex depression. Hopefulness can be enhanced within standard mental health care and in the provision of specific psychotherapeutic interventions. Interventions need to offer a positive relational environment through individual mentor and/or therapeutic relationships and access to groups of youth with similar experiences (Pingitore \& Ferszt, 2017; Walsh \& Minor-Schork, 1997). Professionals encountered should be competent, authentic and communicate hopefulness and unconditional positive regard (Binder et al., 2013; Davidson, 2008; Hambridge, 2017; Midgley et al., 2016). The core interventional tasks appear to be the collaborative setting of personally-relevant goals, engagement in meaningful activity, and scaffolding hopefulness and positive expectancies for goal attainment. The processes of supporting goal identification and progress can be enhanced by drawing on hope theory (Snyder \& Taylor, 2000) and the research evidence presented here; especially with regard to the lived experience mandate to not be directive or prescriptive in attempts to enhance hopefulness. Longer-term and systemic intervention may be needed, especially for people with complex difficulties (Fowler et al., 2019), to gradually build and sustain hopefulness both for the young person and in the wider system. Moreover, whilst youth did hope for psychological change, many hopes and goals related to social recovery. Therefore, professionals should be poised to support youth to enhance their self-agency and pathways thinking across social and occupational life domains, and to use activity and behavioral therapy approaches in their work.

The current study supports a developmental science perspective on hopefulness as an individual level variable that influences and is influenced by the context or ecology around the adolescent (Schmid \& Lopez, 2011). In addition, the study adds two important further considerations. First, 
hopefulness appears to be reduced in the context of complexity, i.e., comorbid mental health problems, social identities and access to support and resources. Secondly, hopefulness influences the degree to which youth engage in relationships and activities which could become hopefulness-inducing, i.e., hope influences mental health help-seeking and treatment engagement. These are important considerations as the developmental science of hopefulness is under-studied especially with reference to diverse and vulnerable youth (Schmid \& Lopez, 2011). Current findings suggest that whilst the "objects" of hopefulness, i.e., the desired future goals, for youth with depression are normative and comparable to adolescents in general (Nurmi, 1991), the process of engendering hopefulness may be more challenging, especially in the context of complexity. Current findings which suggest hope can be increased outside of clinical treatment settings are especially helpful in this regard, as educators and others in the wider surrounding system can offer a hopeful environment which may be missing from the family context. Educators and others can use insights generated in this review, as to the need to gently encourage hopeful thinking in the context of meaningful engagement, ideally involving peers, and with focus on personally-relevant goals. The provision of this hopeful environment should begin the hope-engendering process, which itself will facilitate helpseeking and treatment engagement for youth who need more specialist mental health support. Moreover, the current study furthers understandings of how hopefulness helps adolescents to construct positive ideas and expectations of their future (Schmid et al., 2011) in the context of depression. One lived experience panel member's experience of hopefulness as providing the "mind a little room to wander around" (see Fig. 3) may be a phenomenological manifestation of hopefulness compensating (Sears, 2007) for executive functioning problems observed in adolescence and depression (Luciana, 2016). It must be acknowledged nonetheless, that the current study synthesized findings from studies spanning a large age period (14-25 years) and further research is still needed to consider the impact and enhancement of hopefulness specifically within more narrowly-defined developmental stages (Griggs \& Walker, 2016).

A key implication for policy-makers and commissioners is to consider how best to structure and fund treatment services in supporting professionals' own hopefulness and positive outcome expectancies. Professional hopefulness and expectancies facilitate patient hopefulness (Coppock et al., 2010) and positive clinical and social recovery outcomes (Berry \& Greenwood, 2015; O'Connell \& Stein, 2011), perhaps irrespective of interventions provided (Young et al., 1998). Hopefulness appears to have broad transdiagnostic relevance to treatment engagement and recovery (Schrank et al., 2012), including in anxiety (Gallagher et al., 2020) and psychosis (Berry \& Greenwood, 2015), and in physical illness (Griggs \& Walker, 2016). Therefore, enhancing hopefulness in health service systems clearly aligns with the clinical and diagnostic complexity typically seen in youth (Hickie et al., 2013). Evidence suggests professional hopefulness can be increased through services being recovery-oriented (Niebieszczanski et al., 2016), providing support for coping and managing stress (Larsen et al., 2013), hopeful supervision (Collins, 2015), and regular reflections on beliefs about the therapeutic use of hopefulness (Larsen et al., 2013).

The lived experience panel generated and ranked their top ten future research priorities (Table 4). Important additional priorities include conducting high-quality trials, with long follow-ups and in-built process evaluations to better understand how hopefulness grows and influences clinical and social recovery. Observational and experimental dismantling studies could clarify the necessary and sufficient intervention conditions to improve hopefulness and depression. Such studies could additionally be used to identify the best implicit and explicit relational practices professionals can use to scaffold hopefulness in youth mental health settings. The widespread inclusion of a hopefulness measure in interventional studies in youth depression would facilitate increased intra- and cross-study understandings of its psychotherapeutic qualities. The Trait Hope Scale (Snyder et al., 1991) is recommended as a brief measure which captures dispositional hopefulness; that which underlies more momentary or specific hopes but remains amenable to intervention.

\section{Conclusion}

Hopefulness is important to positive functioning in adolescence, and especially in the recovery of youth with major or complex depression. The current study builds the limited existing understandings of how hopefulness is best enhanced in different treatment settings and how it impacts on important treatment outcomes. The findings of this systematic review and lived experience panel evidence synthesis show that hopefulness can be enhanced in individual and group interventions, brief and longer-term, across health, community and educational settings. Hopefulness facilitates treatment-seeking and engagement and appears self-reinforcing. Specialist intervention is not always needed; hopefulness can be first scaffolded in non-clinical settings. More work is needed to further clarify what works best for whom and when, but current findings emphasize the importance of positive relationship with a professional and/or other youth, the gentle triggering of hopeful thinking, and the identification and pursuit of personally meaningful goals. 
Table 4 Young lived experience expert generated top ten priorities for future research investigating hopefulness as a key active ingredient for youth with major or complex depression

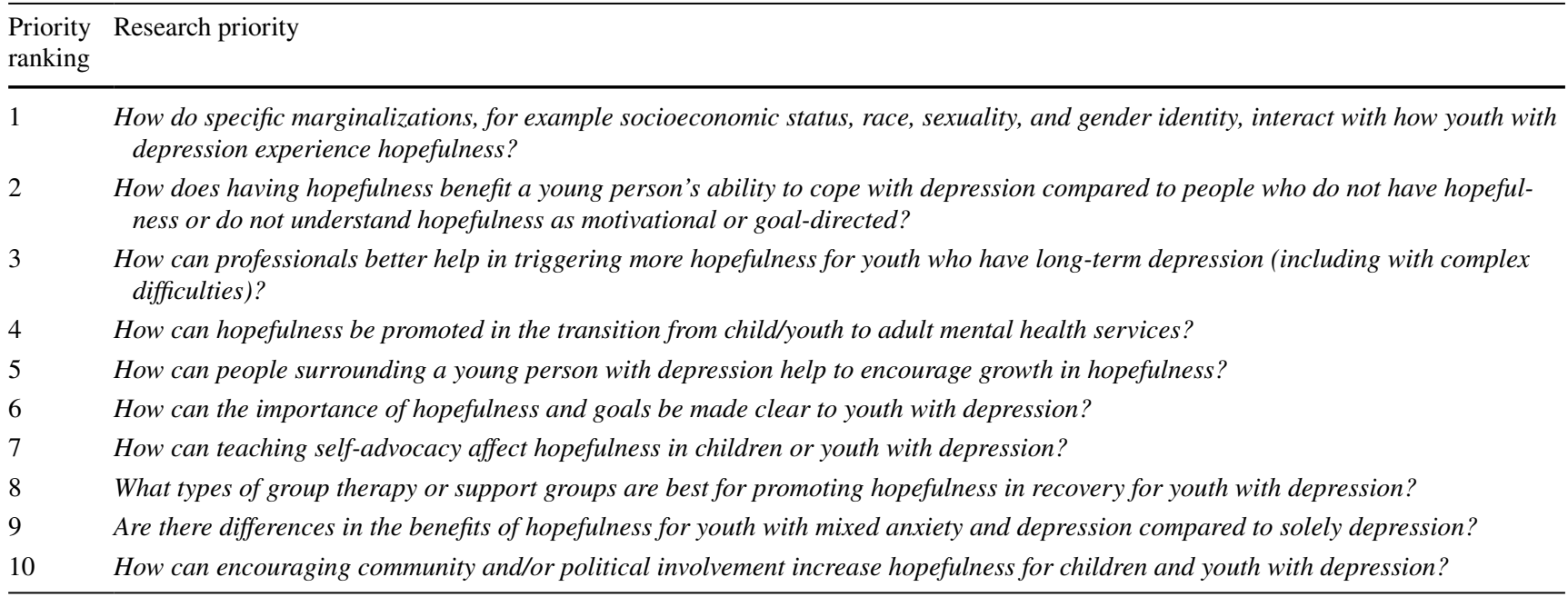

Supplementary Information The online version contains supplementary material available at https://doi.org/10.1007/s40894-021-00167-0.

Acknowledgements We wish to thank the lived experience panel for their contributions, including Lauren Tasker, Jordan Landsborough, Josh, Beth Thomson and Maddy $\mathrm{H}$ and all other young people who participated. Thank you for sharing your incredibly valuable insights and time with us. We wish to thank Abi Thomspon, Becca Randell, Mark Cull and Right Here for their support in convening the lived experience panel.

Authors' Contributions $\mathrm{CB}, \mathrm{DF}, \mathrm{JH}$, and DM designed the study and wrote the protocol. CB, LC, OC, LC, and CS conducted literature searches, risk of bias appraisal, data screening and extraction, and provided summaries of previous research studies. CB conducted the narrative review with support from all authors. $\mathrm{CB}$ wrote the first draft of the manuscript. All authors contributed to and approved the final manuscript.

Funding This work was funded by a Wellcome Trust Insight Analysis Award (June-September 2020). The Wellcome Trust had no role in the study design, collection, analysis or interpretation of the data, writing the manuscript, or decision to submit the paper for publication.

Data Availability There are no new data associated with this manuscript.

\section{Declarations}

Conflict of interest Fowler, Hodgekins, Berry, Sacadura and Crowter have led the creation and evaluation of the Social Recovery Therapy (www.socialrecoverytherapy.co.uk) approach. All other authors declare no conflicts of interest.

Preregistration All research questions, methods and planned analyses used in this review were pre-registered in the review protocol 14/07/2020 (PROSPERO CRD42020192701).

Open Access This article is licensed under a Creative Commons Attribution 4.0 International License, which permits use, sharing, adaptation, distribution and reproduction in any medium or format, as long as you give appropriate credit to the original author(s) and the source, provide a link to the Creative Commons licence, and indicate if changes were made. The images or other third party material in this article are included in the article's Creative Commons licence, unless indicated otherwise in a credit line to the material. If material is not included in the article's Creative Commons licence and your intended use is not permitted by statutory regulation or exceeds the permitted use, you will need to obtain permission directly from the copyright holder. To view a copy of this licence, visit http://creativecommons. org/licenses/by/4.0/.

\section{References}

Alarcon, G. M., Bowling, N. A., \& Khazon, S. (2013). Great expectations: A meta-analytic examination of optimism and hope. Personality and Individual Differences, 54(7), 821-827. https://doi. org/10.1016/J.PAID.2012.12.004

Al-Mabuk, R. H., Enright, R. D., \& Cardis, P. A. (1995). Forgiveness education with parentally love-deprived late adolescents. Journal of Moral Education, 24(4), 427-444. https://doi.org/10.1080/ 0305724950240405

Ambrosini, P. J. (2000). Historical development and present status of the Schedule for Affective Disorders and Schizophrenia for School-Age Children (K-SADS). Journal of the American Academy of Child and Adolescent Psychiatry, 39(1), 49-58. https:// doi.org/10.1097/00004583-200001000-00016

Angold, A., Costello, E. J., Messer, S. C., \& Pickles, A. (1995). Development of a short questionnaire for use in epidemiological studies of depression in children and adolescents. International Journal of Methods in Psychiatric Research, 5(4), 237-249.

Anttila, K., Anttila, M., Kurki, M., Hätönen, H., Marttunen, M., \& Välimäki, M. (2015). Concerns and hopes among adolescents attending adolescent psychiatric outpatient clinics. Child and Adolescent Mental Health, 20(2), 81-88. https://doi.org/10.1111/ camh.12074

Aubuchon-Endsley, N. L., \& Callahan, J. L. (2014). Exploring pretreatment expectancies in a campus mental health setting: The validation of a novel expectancies measure. Journal of College 
Counseling, 17(1), 64-79. https://doi.org/10.1002/j.2161-1882. 2014.00048.x

Bear, H. A., Edbrooke-Childs, J., Norton, S., Krause, K. R., \& Wolpert, M. (2019). Systematic review and meta-analysis: Outcomes of routine specialist mental health care for young people with depression and/or anxiety. Journal of the American Academy of Child \& Adolescent Psychiatry. https://doi.org/10.1016/j.jaac. 2019.12.002

Beck, A. T., Steer, R., \& Brown, G. (1996). Manual for Beck Depression Inventory II. Psychological Corporation.

Beck, A. T., Ward, C. H., Mendelson, M., Mock, J., \& Erbaugh, J. (1961). An inventory for measuring depression. Archives of General Psychiatry, 4(6), 561-571. https://doi.org/10.1001/archpsyc. 1961.01710120031004

Berry, C., \& Greenwood, K. (2015). Hope-inspiring therapeutic relationships, professional expectations and social inclusion for young people with psychosis. Schizophrenia Research, 168(1-2), 153-160. https://doi.org/10.1016/J.SCHRES.2015.07.032

Berry, C., \& Greenwood, K. (2017). Beliefs in social inclusion: Invariance in associations among hope, dysfunctional attitudes, and social inclusion across adolescence and young adulthood. Development and Psychopathology. https://doi.org/10.1017/S0954 579417001195

Bickman, L., Cathay, M. M., Riemer, M., Lambert, E. W., Kelley, S. D., Breda, C., et al. (2010). Manual of the peabody treatment progress battery, 2nd ed. Vanderbilt University.

Binder, P. E., Holgersen, H., \& Moltu, C. (2012). Staying close and reflexive: An explorative and reflexive approach to qualitative research on psychotherapy. Nordic Psychology, 64(2), 103-117. https://doi.org/10.1080/19012276.2012.726815

Binder, P. E., Moltu, C., Sagen, S., Hummelsund, D., \& Holgersen, H. (2013). Unique beings undergoing standard evaluations-A qualitative study of adolescents' experiences of the assessment processes in psychotherapy. Journal of Psychotherapy Integration, 23(2), 107-119. https://doi.org/10.1037/a0031420

Bjärehed, J., Sarkohi, A., \& Andersson, G. (2010). Less positive or more negative? Future-directed thinking in mild to moderate depression. Cognitive Behaviour Therapy, 39(1), 37-45. https:// doi.org/10.1080/16506070902966926

Bjelland, I., Dahl, A. A., Haug, T. T., \& Neckelmann, D. (2002). The validity of the Hospital Anxiety and Depression Scale: An updated literature review. Journal of Psychosomatic Research, 52(2), 69-77. https://doi.org/10.1016/S0022-3999(01)00296-3

Blazer, D. G., Kessler, R. C., McGonagle, K. A., \& Swartz, M. S. (1994). The prevalence and distribution of major depression in a national community sample: The National Comorbidity Survey. American Journal of Psychiatry, 151(7), 979-986. https://doi. org/10.1176/ajp.151.7.979

Bolier, L., Haverman, M., Westerhof, G. J., Riper, H., Smit, F., \& Bohlmeijer, E. (2013). Positive psychology interventions: A meta-analysis of randomized controlled studies. BMC Public Health, 13(1), 119. https://doi.org/10.1186/1471-2458-13-119

Bordin, E. S. (1994). Theory and research on the therapeutic working alliance: New directions. In O. Horvath, \& L. S. Greenberg (Eds.), Wiley series on personality processes. The working alliance: Theory, research, and practice (pp. 13-37). Wiley.

Braun, V., \& Clarke, V. (2006). Using thematic analysis in psychology. Qualitative Research in Psychology, 3(2), 77-101. https://doi. org/10.1191/1478088706qp063oa

Bury, C., Raval, H., \& Lyon, L. (2007). Young people's experiences of individual psychoanalytic psychotherapy. Psychology and Psychotherapy: Theory, Research and Practice, 80(1), 79-96. https://doi.org/10.1348/147608306X109654

Campbell, M., McKenzie, J. E., Sowden, A., Katikireddi, S. V., Brennan, S. E., Ellis, S., et al. (2020). Synthesis without meta-analysis
(SWiM) in systematic reviews: Reporting guideline. The BMJ. https://doi.org/10.1136/bmj.16890

Clarke, D. (2003). Faith and hope. Australasian Psychiatry, 11, 164 168. https://doi.org/10.1046/j.1039-8562.2003.00550.x

Collins, S. (2015). Hope and helping in social work. Practice, 27(3), 197-213. https://doi.org/10.1080/09503153.2015.1014335

Conklin, L. R. (2009). The effect of a brief goal-skills group intervention on homework compliance and depressive symptom severity. The Ohio State University.

Cooke, A., Smith, D., \& Booth, A. (2012). Beyond PICO: The SPIDER tool for qualitative evidence synthesis. Qualitative Health Research, 22(10), 1435-1443. https://doi.org/10.1177/10497 32312452938

Coppock, T. E., Owen, J. J., Zagarskas, E., \& Schmidt, M. (2010). The relationship between therapist and client hope with therapy outcomes. Psychotherapy Research, 20(6), 619-626. https://doi. org/10.1080/10503307.2010.497508

Corbin, J., \& Strauss, A. (2008). Basics of qualitative research: Techniques and procedures for developing grounded theory (Third.). SAGE Publications, Inc. https://doi.org/10.4135/9781452230153

Costello, E. J., Angold, A., Burns, B. J., Erkanli, A., Stangl, D. K., $\&$ Tweed, D. L. (1996). The Great Smoky Mountains Study of Youth. Functional impairment and serious emotional disturbance. Archives of General Psychiatry, 53(12), 1137-1143.

Cutcliffe, J. R., \& Koehn, C. V. (2007). Hope and interpersonal psychiatric/mental health nursing: A systematic review of the literature? Part two. Journal of Psychiatric and Mental Health Nursing, 14(2), 141-147. https://doi.org/10.1111/j.1365-2850. 2007.01055.x

Danermark, B., Ekström, M., \& Karlsson, J. C. (2002). Explaining society: Critical realism in the social sciences. (M. Ekström, B. Danermark, J. C. Karlsson, \& L. Jakobsen, Eds.). Routledge.

Davidson, M. (2008). "You have to have the relationship": A youth perspective on psychotherapy and the development of a therapeutic relationship. Simon Fraser University. Retrieved from https:// summit.sfu.ca/item/12536

Dew-Reeves, S. E., Michele Athay, M., \& Kelley, S. D. (2012). Validation and use of the children's hope scale-revised PTPB edition (CHS-PTPB): High initial youth hope and elevated baseline symptomatology predict poor treatment outcomes. Administration and Policy in Mental Health and Mental Health Services Research, 39(1-2), 60-70. https://doi.org/10.1007/ s10488-012-0411-2

Diener, E., Emmons, R. A., Larsem, R. J., \& Griffin, S. (1985). The satisfaction with life scale. Journal of Personality Assessment, 49(1), 71-75. https://doi.org/10.1207/s15327752jpa4901_13

Dimidjian, S., Martell, C. R., Addis, M. E., \& Herman-Dunn, R. (2008). Behavioral activation for depression. In Clinical handbook of psychological disorders: A step-by-step treatment manual (pp. 328-364). The Guildford Press.

Dowling, M., \& Rickwood, D. (2015). Investigating individual online synchronous chat counselling processes and treatment outcomes for young people. Advances in Mental Health, 12(3), 216-224. https://doi.org/10.1080/18374905.2014.11081899

Dryden, W., DiGiuseppe, R., \& Neenan, M. (2010). A primer on rational emotive behaviour therapy. Research Press.

Dufault, K., \& Martocchio, B. C. (1985). Symposium on compassionate care and the dying experience. Hope: Its spheres and dimensions. The Nursing Clinics of North America, 20(2), 379-391.

Ebesutani, C., Reise, S. P., Chorpita, B. F., Ale, C., Regan, J., Young, J., et al. (2012). The Revised Child Anxiety and Depression Scale-Short Version: Scale reduction via exploratory bifactor modeling of the broad anxiety factor. Psychological Assessment, 24(4), 833-845. https://doi.org/10.1037/a0027283

Eckshtain, D., Kuppens, S., Ugueto, A., Ng, M. Y., Vaughn-Coaxum, R., Corteselli, K., \& Weisz, J. R. (2020, January). Meta-analysis: 
13-year follow-up of psychotherapy effects on youth depression. Journal of the American Academy of Child and Adolescent Psychiatry. https://doi.org/10.1016/j.jaac.2019.04.002

Edbrooke-Childs, J., Wolpert, M., Zamperoni, V., Napoleone, E., \& Bear, H. (2018). Evaluation of reliable improvement rates in depression and anxiety at the end of treatment in adolescents. Bjpsych Open, 4(4), 250-255. https://doi.org/10.1192/bjo.2018. 31

Elo, S., \& Kyngäs, H. (2008). The qualitative content analysis process. Journal of Advanced Nursing, 62(1), 107-115. https://doi.org/10. 1111/j.1365-2648.2007.04569.x

Endicott, J., Nee, J., Harrison, W., \& Blumenthal, R. (1993). Quality of life enjoyment and satisfaction questionnaire: A new measure. Psychopharmacology Bulletin, 29(2), 321-326.

Enright, R. D., \& Fitzgibbons, R. P. (2000). Helping clients forgive: An empirical guide for resolving anger and restoring hope. Helping clients forgive: An empirical guide for resolving anger and restoring hope. American Psychological Association. https://doi. org/10.1037/10381-000

Esteves, M., Scoloveno, R. L., Mahat, G., Yarcheski, A., \& Scoloveno, M. A. (2013, April). An integrative review of adolescent hope. Journal of Pediatric Nursing. https://doi.org/10.1016/j.pedn. 2012.03.033

Faulstich, M., Carey, M., Ruggiero, L., Enyart, P., \& Gresham, F. (2017). Center for Epidemiological Studies Depression Scale for Children (CES-DC). Retrieved September 28, 2020, from https://www.theshapesystem.com/wp-content/uploads/2019/09/ CES-DC_FINAL_11.29.17.pdf

Feldman, D. B., \& Dreher, D. E. (2012). Can hope be changed in 90 minutes? Testing the efficacy of a single-session goal-pursuit intervention for college students. Journal of Happiness Studies, 13(4), 745-759. https://doi.org/10.1007/s10902-011-9292-4

Fendrich, M., Weissman, M. M., \& Warner, V. (1990). Screening for depressive disorder in children and adolescents: Validating the Center for Epidemiologic Studies Depression Scale for children. American Journal of Epidemiology, 131(3), 538-551. https://doi. org/10.1093/oxfordjournals.aje.a115529

Field, A. (2013). Discovering statistics using IBM SPSS. SAGE Publications Ltd.

Fowler, D., French, P., Banerjee, R., Barton, G., Berry, C., Byrne, R., et al. (2017). Prevention and treatment of long-term social disability amongst young people with emerging severe mental illness with social recovery therapy (The PRODIGY Trial): Study protocol for a randomised controlled trial. Trials. https://doi.org/ 10.1186/s13063-017-2062-9

Fowler, D., French, P., Hodgekins, J., Lower, R., Turner, R., Burton, S., \& Wilson, J. (2013). CBT to address and prevent social disability in early and emerging psychosis. In CBT for Schizophrenia (pp. 143-167). Wiley. https://doi.org/10.1002/9781118330029.ch8

Fowler, D., Hodgekins, J., Arena, K., Turner, R., Lower, R., Wheeler, K., et al. (2010). Early detection and psychosocial intervention for young people who are at risk of developing long term socially disabling severe mental illness: Should we give equal priority to functional recovery and complex emotional dysfunction as to psychotic symptom. Clinical Neuropsychiatry, 7(2), 63-72.

Fowler, D., Hodgekins, J., Berry, C., Clarke, T., Palmier-Claus, J., Sacadura, C., et al. (2019). Social recovery therapy: A treatment manual. Psychosis, 11, 261-272.

Fowler, D., Hodgekins, J., French, P., Marshall, M., Freemantle, N., McCrone, P., et al. (2018). Social recovery therapy in combination with early intervention services for enhancement of social recovery in patients with first-episode psychosis (SUPEREDEN3): A single-blind, randomised controlled trial. The Lancet Psychiatry, 5(1), 41-50. https://doi.org/10.1016/S2215-0366(17) 30476-5
Freud, S. (1953). (n.d.). Psychical (or mental) treatment. In J. Trans, Strachey (Ed.), The complete psychological works of Sigmund Freud (Vol VII). Hogarth Press.

Gabrielsen, L. E., Eskedal, L. T., Mesel, T., Aasen, G. O., Hirte, M., Kerlefsen, R. E., et al. (2019). The effectiveness of wilderness therapy as mental health treatment for adolescents in Norway: A mixed methods evaluation. International Journal of Adolescence and Youth, 24(3), 282-296. https://doi.org/10.1080/02673843. 2018.1528166

Gallagher, M. W., Long, L. J., Richardson, A., D’Souza, J., Boswell, J. F., Farchione, T. J., \& Barlow, D. H. (2020). Examining hope as a transdiagnostic mechanism of change across anxiety disorders and CBT treatment protocols. Behavior Therapy, 51(1), 190-202. https://doi.org/10.1016/j.beth.2019.06.001

Gallagher, M. W., Smith, L. J., Richardson, A. L., D'Souza, J. M., \& Long, L. J. (2021). Examining the longitudinal effects and potential mechanisms of hope on COVID-19 stress, anxiety, and well-being. Cognitive Behaviour Therapy. https://doi.org/10. 1080/16506073.2021.1877341

Gee, B., Notley, C., Byrne, R., Clarke, T., Hodgekins, J., French, P., \& Fowler, D. (2018). Young people's experiences of Social Recovery Cognitive Behavioural Therapy and treatment as usual in the PRODIGY trial. Early Intervention in Psychiatry, 12(5), 879-885. https://doi.org/10.1111/eip.12381

Gillig, T. K., Miller, L. C., \& Cox, C. M. (2019). "She finally smiles ... for real": Reducing depressive symptoms and bolstering resilience through a camp intervention for LGBTQ youth. Journal of Homosexuality, 66(3), 368-388. https://doi.org/10.1080/00918 369.2017.1411693

Glasgow, R. E., Vogt, T. M., \& Boles, S. M. (1999). Evaluating the public health impact of health promotion interventions: The RE-AIM framework. American Journal of Public Health, 89(9), 1322-1327. https://doi.org/10.2105/AJPH.89.9.1322

Goldman-Mellor, S., Caspi, A., Arseneault, L., Ajala, N., Ambler, A., Danese, A., et al. (2016). Committed to work but vulnerable: Self-perceptions and mental health in NEET 18-year olds from a contemporary British cohort. Journal of Child Psychology and Psychiatry, 57(2), 196-203. https://doi.org/10.1111/jcpp.12459

Gomez, F. (2016). A guide to the Depression, Anxiety and Stress Scale (DASS 21). Retrieved September 28, 2020, from https://www. academia.edu/25177167/A_Guide_to_the_Depression_Anxiety_ and_Stress_Scale_DASS_21

Graneheim, U. H., \& Lundman, B. (2004). Qualitative content analysis in nursing research: Concepts, procedures and measures to achieve trustworthiness. Nurse Education Today, 24(2), 105-112. https://doi.org/10.1016/j.nedt.2003.10.001

Green, L. S., \& Grant, A. M. (2006). Cognitive-behavioral, solutionfocused life coaching: Enhancing goal striving, well-being, and hope. Journal of Positive Psychology, 1(3), 142-149. https://doi. org/10.1080/17439760600619849

Green, S., Grant, A., \& Rynsaardt, J. (2007). Evidence-based life coaching for senior high school students: Building hardiness and hope. International Coaching Psychology Review, 2(1), 24-32.

Griggs, S. (2017). Hope and mental health in young adult college students: An integrative review. Journal of Psychosocial Nursing and Mental Health Services, 55(2), 28-35. https://doi.org/10. 3928/02793695-20170210-04

Griggs, S., \& Walker, R. K. (2016, July). The role of hope for adolescents with a chronic illness: An integrative review. Journal of Pediatric Nursing. https://doi.org/10.1016/j.pedn.2016.02.011

Hambridge, S. (2017). What does it mean to young people to be part of a care farm? An evaluation of a care farm intervention for young people with behavioural, emotional and social difficulties. Bournemouth University.

Hamilton, M. (1967). Development of a rating scale for primary depressive illness. British Journal of Social and Clinical Psychology, 
6(4), 278-296. https://doi.org/10.1111/j.2044-8260.1967.tb005 30.

Harris, J., Croot, L., Thompson, J., \& Springett, J. (2016). How stakeholder participation can contribute to systematic reviews of complex interventions. Journal of Epidemiology and Community Health, 70(2), 207-214. https://doi.org/10.1136/ jech-2015-205701

Health Research Council of New Zealand. (2010). Guidelines for researchers on health research involving Māori. Auckland, New Zealand. Retrieved September 23, 2020, from https://gateway. hrc.govt.nz/funding/downloads/Guidelines_for_researchers_on_ health_research_involving_Māori.pdf

Heidegger, M. (1996). Being and time: A translation of Sein und Zeit. State University of New York Press.

Henry, J. D., \& Crawford, J. R. (2005). The short-form version of the Depression anxiety stress scales (DASS-21): Construct validity and normative data in a large non-clinical sample. British Journal of Clinical Psychology, 44(2), 227-239. https://doi.org/10. 1348/014466505X29657

Herth, K. (1991). Development and refinement of an instrument to measure hope. Scholarly Inquiry for Nursing Practice, 5(1), $39-51$.

Herth, K. (1992). Abbreviated instrument to measure hope: Development and psychometric evaluation. Journal of Advanced Nursing, 17(10), 1251-1259. https://doi.org/10.1111/j.1365-2648.1992. tb01843.x

Hickie, I. B., Scott, E. M., Hermens, D. F., Naismith, S. L., Guastella, A. J., Kaur, M., et al. (2013). Applying clinical staging to young people who present for mental health care. Early Intervention in Psychiatry, 7(1), 31-43. https://doi.org/10.1111/j.1751-7893. 2012.00366.x

Hirsch, J. K., Visser, P. L., Chang, E. C., \& Jeglic, E. L. (2012). Race and ethnic differences in hope and hopelessness as moderators of the association between depressive symptoms and suicidal behavior. Journal of American College Health, 60(2), 115-125. https://doi.org/10.1080/07448481.2011.567402

Hodgekins, J., French, P., Birchwood, M., Mugford, M., Christopher, R., Marshall, M., et al. (2015). Comparing time use in individuals at different stages of psychosis and a non-clinical comparison group. Schizophrenia Research, 161(2-3), 188-193. https://doi. org/10.1016/j.schres.2014.12.011

Hollway, W., \& Jefferson, T. (2000). Doing qualitative research differently: Free association, narrative and the narrative method. Sage.

Hong, Q. N., Pluye, P., Fàbregues, S., Bartlett, G., Boardman, F., Cargo, M., et al. (2018, August 1). Mixed Methods Appraisal Tool (MMAT) Version 2018. McGill.

Hong, Q. N., Pluye, P., Fàbregues, S., Bartlett, G., Boardman, F., Cargo, M., et al. (2019). Improving the content validity of the mixed methods appraisal tool: A modified e-Delphi study. Journal of Clinical Epidemiology, 111, 49-59.e1. https://doi.org/10. 1016/j.jclinepi.2019.03.008

Hu, Y., Ye, B., \& Im, H. (2021). Hope and post-stress growth during COVID-19 pandemic: The mediating role of perceived stress and the moderating role of empathy. Personality and Individual Differences, 178, 110831. https://doi.org/10.1016/j.paid.2021. 110831

Hughes, J. R., Clark, S. E., Wood, W., Cakmak, S., Cox, A., Macinnis, M., et al. (2010). Youth homelessness: The relationships among mental health, hope, and service satisfaction. Journal of the Canadian Academy of Child and Adolescent Psychiatry, 19(4), 274-283.

Isa, E. W., Ani, C., Bella-Awusah, T., \& Omigbodun, O. (2018). Effects of psycho-education plus basic cognitive behavioural therapy strategies on medication-treated adolescents with depressive disorder in Nigeria. Journal of Child and Adolescent Mental Health, 30(1), 11-18. https://doi.org/10.2989/17280583.2018. 1424634

Jevne, R. F. (2005). Hope: The simplicity and complexity. In J. A. Eliott (Ed.), Interdisciplinary perspectives on hope (pp. 259-289). Nova Science Publishers, Inc.

Johnson, R. B., \& Onwuegbuzie, A. J. (2004). Mixed methods research: A research paradigm whose time has come. Educational Researcher, 33(7), 14-26. https://doi.org/10.3102/00131 89X033007014

Kessler, R. C., Amminger, G. P., Aguilar-Gaxiola, S., Alonso, J., Lee, S., \& Ustün, T. B. (2007). Age of onset of mental disorders: A review of recent literature. Current Opinion in Psychiatry, 20(4), 359-364. https://doi.org/10.1097/YCO.0b013e32816ebc8c

Kessler, R. C., Sampson, N. A., Berglund, P., Gruber, M. J., AlHamzawi, A., Andrade, L., et al. (2015). Anxious and non-anxious major depressive disorder in the World Health Organization World Mental Health Surveys. Epidemiology and Psychiatric Sciences, 24(3), 210-226. https://doi.org/10.1017/S204579601 5000189

Koehn, C. V., \& Cutcliffe, J. R. (2007). Hope and interpersonal psychiatric/mental health nursing: A systematic review of the literature? Part one. Journal of Psychiatric and Mental Health Nursing, 14(2), 134-140. https://doi.org/10.1111/j.1365-2850. 2007.01054.x

Kroenke, K., Spitzer, R. L., \& Williams, J. B. W. (2001). The PHQ9: Validity of a brief depression severity measure. Journal of General Internal Medicine, 16(9), 606-613. https://doi.org/10. 1046/j.1525-1497.2001.016009606.x

Larsen, D. J., Stege, R., \& Flesaker, K. (2013). 'It's important for me not to let go of hope': Psychologists' in-session experiences of hope. Reflective Practice, 14(4), 472-486. https://doi.org/10. 1080/14623943.2013.806301

Laverty, S. M. (2003). Hermeneutic phenomenology and phenomenology: A comparison of historical and methodological considerations. International Journal of Qualitative Methods, 2(3), 21-35.

Leavey, J. E. (2005). Youth experiences of living with mental health problems: Emergence, loss, adaptation and recovery (ELAR). Canadian Journal of Community Mental Health, 24(2), 109-126. https://doi.org/10.7870/cjcmh-2005-0018

Leibovich, L., Wachtel, P. L., Nof, A., \& Zilcha-Mano, S. (2020). "Take a sad song and make it better": What makes an interpretation growth facilitating for the patient? Psychotherapy. https:// doi.org/10.1037/pst0000290

Lenhard, W., \& Lenhard, A. (2016). Calculation of effect sizes. Dettelbach. https://doi.org/10.13140/RG.2.2.17823.92329

Lin, W. N., Enright, R. D., \& Klatt, J. S. (2013). A forgiveness intervention for Taiwanese young adults with insecure attachment. Contemporary Family Therapy, 35, 105-120. https://doi.org/10. 1007/s10591-012-9218-2

Lin, X., Fang, X., Chi, P., Li, X., Chen, W., \& Heath, M. A. (2014). Grief-processing-based psychological intervention for children orphaned by AIDS in central China: A pilot study. School Psychology International, 35(6), 609-626. https://doi.org/10.1177/ 0143034314535617

Loveday, P. M., Lovell, G. P., \& Jones, C. M. (2018). The best possible selves intervention: A review of the literature to evaluate efficacy and guide future research. Journal of Happiness Studies, 19(2), 607-628. https://doi.org/10.1007/s10902-016-9824-z

Lovibond, S. H., \& Lovibond, P. F. (1995). Manual for the Depression Anxiety Stress Scales. Psychology Foundation Monograph. (2nd ed.). Psychology Foundation of Australia.

Luciana, M. (2016). Executive function in adolescence: A commentary on regulatory control and depression in adolescents: Findings from neuroimaging and neuropsychological research. Journal of 
Clinical Child and Adolescent Psychology, 45(1), 84-89. https:// doi.org/10.1080/15374416.2015.1123638

Lydon-Staley, D. M., Xia, M., Mak, H. W., \& Fosco, G. M. (2019). Adolescent emotion network dynamics in daily life and implications for depression. Journal of Abnormal Child Psychology, 47(4), 717-729. https://doi.org/10.1007/s10802-018-0474-y

Magaletta, P. R., \& Oliver, J. M. (1999). The hope construct, will, and ways: Their relations with self-efficacy, optimism, and general well-being. Journal of Clinical Psychology, 55(5), 539-551. https://doi.org/10.1002/(SICI)1097-4679(199905)55:5\%3c539:: AID-JCLP2\%3e3.0.CO;2-G

Mahood, Q., Van Eerd, D., \& Irvin, E. (2014). Searching for grey literature for systematic reviews: Challenges and benefits. Research Synthesis Methods, 5(3), 221-234. https://doi.org/10.1002/jrsm. 1106

Marques, S. C., \& Lopez, S. J. (2014). The promotion of hope in children and youth (pp. 187-197). https://doi.org/10.1007/978-94017-8669-0_12

McDowell, I. (2006). Measuring health: A guide to rating scales and questionnaires (Third.). Oxford University Press.

McMillan, S. S., King, M., \& Tully, M. P. (2016, June 1). How to use the nominal group and Delphi techniques. International Journal of Clinical Pharmacy. https://doi.org/10.1007/ s11096-016-0257-x

Melchior, L. A., Huba, G. J., Brown, V. B., \& Reback, C. J. (1993). A short depression index for women. Educational and Psychological Measurement, 53(4), 1117-1125. https://doi.org/10.1177/ 0013164493053004024

Menninger, K. (1959). The academic lecture: Hope. American Journal of Psychiatry, 116(6), 481-491. https://doi.org/10.1176/ajp. 116.6.481

Merry, S. N., Stasiak, K., Shepherd, M., Frampton, C., Fleming, T., \& Lucassen, M. F. G. (2012). The effectiveness of SPARX, a computerised self help intervention for adolescents seeking help for depression: Randomised controlled non-inferiority trial. British Medical Journal. https://doi.org/10.1136/bmj.e2598

Metsäranta, K., Kurki, M., Valimaki, M., \& Anttila, M. (2019). How do adolescents use electronic diaries? A mixed-methods study among adolescents with depressive symptoms. Journal of Medical Internet Research. https://doi.org/10.2196/11711

Midgley, N., Ansaldo, F., Parkinson, S., Holmes, J., Stapley, E., \& Target, M. (2011). Expectations of therapy interview (young person and parent versions). Unpublished manuscript, Anna Freud Centre, London.

Midgley, N., Holmes, J., Parkinson, S., Stapley, E., Eatough, V., \& Target, M. (2016). "Just like talking to someone about like shit in your life and stuff, and they help you": Hopes and expectations for therapy among depressed adolescents. Psychotherapy Research, 26(1), 11-21. https://doi.org/10.1080/10503307.2014. 973922

Moher, D., Liberati, A., Tetzlaff, J., \& Altman, D. G. (2009). Preferred reporting items for systematic reviews and meta-analyses: The PRISMA statement. PLoS Medicine, 6(7), e1000097. https://doi. org/10.1371/journal.pmed.1000097

Morina, N., Deeprose, C., Pusowski, C., Schmid, M., \& Holmes, E. A. (2011). Prospective mental imagery in patients with major depressive disorder or anxiety disorders. Journal of Anxiety Disorders, 25(8), 1032-1037. https://doi.org/10.1016/j.janxdis. 2011.06.012

Morris, S. B. (2008). Estimating effect sizes from pretest-posttestcontrol group designs. Organizational Research Methods, 11(2), 364-386. https://doi.org/10.1177/1094428106291059

Morris, S. B., \& DeShon, R. P. (2002). Combining effect size estimates in meta-analysis with repeated measures and independent-groups designs. Psychological Methods, 7(1), 105-125. https://doi.org/ 10.1037/1082-989X.7.1.105
Neill, J. T., Marsh, H. W., \& Richards, G. E. (2003). The Life Effectiveness Questionnaire: Development and psychometrics. University of Western Sydney, Sydney.

Nelson, B., Sass, L. A., \& Skodlar, B. (2009). The phenomenological model of psychotic vulnerability and its possible implications for psychological interventions in the ultra-high risk ('prodromal') population. Psychopathology, 42(5), 283-292. https://doi.org/10. $1159 / 000228837$

Niebieszczanski, R. J., Dent, H., \& McGowan, A. (2016). "Your personality is the intervention": A grounded theory of mental health nurses' beliefs about hope and experiences of fostering hope within a secure setting. The Journal of Forensic Psychiatry \& Psychology, 27(3), 419-442. https://doi.org/10.1080/14789949. 2015.1134626

Nunn, K. P. (1996). Personal hopefulness: A conceptual review of the relevance of the perceived future to psychiatry. British Journal of Medical Psychology, 69(3), 227-245. https://doi.org/10.1111/j. 2044-8341.1996.tb01866.x

Nurmi, J. E. (1991, March 1). How do adolescents see their future? A review of the development of future orientation and planning. Developmental Review. https://doi.org/10.1016/0273-2297(91) 90002-6

O'Connell, M. J., \& Stein, C. H. (2011). The relationship between case manager expectations and outcomes of persons diagnosed with schizophrenia. Community Mental Health Journal, 47(4), 424-435. https://doi.org/10.1007/s10597-010-9337-x

Osborn, M., \& Smith, J. A. (1998). The personal experience of chronic benign lower back pain: An interpretative phenomenological analysis. British Journal of Health Psychology, 3(1), 65-83. https://doi.org/10.1111/j.2044-8287.1998.tb00556.x

Oxman, A. D. (2004). Grading quality of evidence and strength of recommendations. British Medical Journal, 328(7454), 1490-1494. https://doi.org/10.1136/bmj.328.7454.1490

Oyserman, D. (2001). Self-concept and identity. In A. Tesser, \& N. Schwarz (Eds.), The Blackwell Handbook of Social Psychology (pp. 499-517). Blackwell.

Parse, R. R. (1993). The experience of laughter: A phenomenological study. Nursing Science Quarterly, 6(1), 39-43. https://doi.org/ $10.1177 / 089431849300600110$

Pingitore, F., \& Ferszt, G. G. (2017). The "voice" and perspectives of adolescents participating in a short-term psychotherapy group. International Journal of Group Psychotherapy, 67(3), 360-382. https://doi.org/10.1080/00207284.2016.1260460

Popay, J., Roberts, H., Sowden, A., Petticrew, M., Arai, L., Rodgers, M., et al. (2006). Guidance on the conduct of narrative synthesis in systematic reviews: A product from the ESRC Methods Programme. https://doi.org/10.13140/2.1.1018.4643

Poznanski, E. O., Grossman, J. A., Buchsbaum, Y., Banegas, M., Freeman, L., \& Gibbons, R. (1984). Preliminary studies of the reliability and validity of the Children's Depression Rating Scale. Journal of theAmerican Academy of Child Psychiatry. https:// doi.org/10.1097/00004583-198403000-00011

Proctor, C., Tsukayama, E., Wood, A. M., Maltby, J., Eades, J. F., \& Linley, P. A. (2011). Strengths gym: The impact of a character strengths-based intervention on the life satisfaction and well-being of adolescents. Journal of Positive Psychology, 6(5), 377-388. https://doi.org/10.1080/17439760.2011.594079

Qualtrics. (2020). Qualtrics. Provo, Utah. https://www.qualtrics.com

Radloff, L. S. (1977). The CES-D scale: A self-report depression scale for research in the general population. Applied Psychological Measurement, 1(3), 385-401. https://doi.org/10.1177/01466 2167700100306

Rayner, S., Thielking, M., \& Lough, R. (2018). A new paradigm of youth recovery: Implications for youth mental health service provision. Australian Journal of Psychology, 70(4), 330-340. https://doi.org/10.1111/ajpy.12206 
Reilly, C., Atkinson, P., Memon, A., Jones, C., Dabydeen, L., Das, K. B., et al. (2018). Symptoms of depression, anxiety, and stress in parents of young children with epilepsy: A case controlled population-based study. Epilepsy and Behavior, 80, 177-183. https://doi.org/10.1016/j.yebeh.2017.12.020

Ritchie, J., Spencer, L., \& Spencer, L. (2002). Qualitative data analysis for applied policy research. In A. M. Huberman, \& M. B. Miles (Eds.), The Qualitative Researcher's Companion (pp. 187-208). Routledge. https://doi.org/10.4324/9780203413081-14

Ritschel, L. A., Ramirez, C. L., Cooley, J. L., \& Edward Craighead, W. (2016). Behavioral activation for major depression in adolescents: Results from a pilot study. Clinical Psychology: Science and Practice, 23(1), 39-57. https://doi.org/10.1111/cpsp.12140

Ritschel, L. A., Ramirez, C. L., Jones, M., \& Craighead, W. E. (2011). Behavioral activation for depressed teens: A pilot study. Cognitive and Behavioral Practice, 18(2), 281-299. https://doi.org/10. 1016/j.cbpra.2010.07.002

Sælid, G. A., \& Nordahl, H. M. (2017). Rational emotive behaviour therapy in high schools to educate in mental health and empower youth health. A randomized controlled study of a brief intervention. Cognitive Behaviour Therapy, 46(3), 196-210. https://doi. org/10.1080/16506073.2016.1233453

Sandelowski, M. (2000). Focus on research methods: Whatever happened to qualitative description? Research in Nursing and Health, 23(4), 334-340. https://doi.org/10.1002/1098240x(200008)23:4\%3c334::aid-nur9\%3e3.0.co;2-g

Schmid, K. L., \& Lopez, J. S. (2011). Positive pathways to adulthood: The role of hope in adolescents' constructions of their futures. Advances in Child Development and Behavior, 41, 69-88. https:// doi.org/10.1016/B978-0-12-386492-5.00004-X

Schmid, K. L., Phelps, E., Kiely, M. K., Napolitano, C. M., Boyd, M. J., \& Lerner, R. M. (2011). The role of adolescents' hopeful futures in predicting positive and negative developmental trajectories: Findings from the 4-H Study of Positive Youth Development. Journal of Positive Psychology, 6(1, SI), 45-56. https://doi.org/ 10.1080/17439760.2010.536777

Schrank, B., Bird, V., Rudnick, A., \& Slade, M. (2012). Determinants, self-management strategies and interventions for hope in people with mental disorders: Systematic search and narrative review. Social Science and Medicine, 74(4), 554-564. https://doi.org/10. 1016/j.socscimed.2011.11.008

Schrank, B., Stanghellini, G., \& Slade, M. (2008). Hope in psychiatry: A review of the literature. Acta Psychiatrica Scandinavica, 118(6), 421-433. https://doi.org/10.1111/j.1600-0447.2008. 01271.x

Schubert, T., Eloo, R., Scharfen, J., \& Morina, N. (2020). How imagining personal future scenarios influences affect: Systematic review and meta-analysis. Clinical Psychology Review, 75, 101811. https://doi.org/10.1016/j.cpr.2019.101811

Sears, K. (2007). The relationship between hope, executive function, behavioral/emotional strengths and school functioning in 5th and 6th grade students. undefined. The Ohio State University.

Shek, D. T. L., Leung, H., \& Wu, F. K. Y. (2017). Hope, aspirations, and resilience in children and adolescents: A review of research on measurement and related antecedents. International Journal on Disability and Human Development, 16(4), 351-358. https:// doi.org/10.1515/ijdhd-2017-7003

Shepherd, M., Merry, S., Lambie, I., \& Thompson, A. (2018). Indigenous adolescents $\Leftrightarrow$ perception of an emental health program (SPARX): Exploratory qualitative assessment. Journal of Medical Internet Research Serious Games, 20(7), e13. https://doi.org/ 10.2196/games. 8752

Short, S. (2006). Review of the UK 2000 Time Use Survey. London. https://scholar.google.co.uk/scholar?cluster=126473022650024 00979\&hl=en\&as_sdt $=0,5$
Simonds, L. M., Pons, R. A., Stone, N. J., Warren, F., \& John, M. (2014). Adolescents with anxiety and depression: Is social recovery relevant? Clinical Psychology and Psychotherapy, 21(4), 289-298. https://doi.org/10.1002/cpp.1841

Sin, N. L., \& Lyubomirsky, S. (2009). Enhancing well-being and alleviating depressive symptoms with positive psychology interventions: A practice-friendly meta-analysis. Journal of Clinical Psychology, 65(5), 467-487. https://doi.org/10.1002/jclp.20593

Smith, J. A. (1996). Beyond the divide between cognition and discourse: Using interpretative phenomenological analysis in health psychology. Psychology and Health, 11(2), 261-271. https://doi. org/10.1080/08870449608400256

Smith, J. A. (2007). Hermeneutics, human sciences and health: Linking theory and practice. International Journal of Qualitative Studies on Health and Well-Being, 2(1), 3-11. https://doi.org/10.1080/ 17482620601016120

Smith, J. A., Flowers, P., \& Larkin, M. (2012). Interpretative phenomenological analysis. Theory, method and research. Sage Publications.

Smith, J. A., Flowers, P., \& Osborn, M. (1997). Interpretative phenomenological analysis and the psychology of health and illness. In L. Yardley (Ed.), Material discourses of health and illness ( $\mathrm{p}$. 68). Routledge

Smith, J. A., \& Osborn, M. (2008). Interpretative phenomenological analysis. In Doing social psychology research (pp. 229-254). The British Psychological Society and Blackwell Publishing Ltd. https://doi.org/10.1002/9780470776278.ch10

Smith, J. A., Greer, T., Sheets, T., \& Watson, S. (2011). Is there more to yoga than exercise? Alternative Therapies in Health and Medicine, 17(3), 22-29.

Snyder, C. R. (2000). The past and possible futures of hope. Journal of Social and Clinical Psychology, 19(1), 11-28. https://doi.org/ 10.1521/jscp.2000.19.1.11

Snyder, C. R., Harris, C., Anderson, J. R., Holleran, S. A., Irving, L. M., Sigmon, S. T., et al. (1991). The will and the ways: Development and validation of an individual-differences measure of hope. Journal of Personality and Social Psychology, 60(4), 570-585. https://doi.org/10.1037/0022-3514.60.4.570

Snyder, C. R., Hoza, B., Pelham, W. E., Rapoff, M., Ware, L., \& Danovsky, M. (1997). The development and validation of the Children's Hope Scale. Journal of Pediatric Psychology, 22, 399-421. https://doi.org/10.1093/jpepsy/22.3.399

Snyder, C. R., Sympson, S. C., Ybasco, F. C., Borders, T. F., Babyak, M. A., \& Higgins, R. L. (1996). Development and validation of the State Hope Scale. Journal of Personality and Social Psychology, 70(2), 321-335. https://doi.org/10.1037/0022-3514.70.2.321

Snyder, C. R., \& Taylor, J. D. (2000). Hope as a common factor across psychotherapy approaches. In Handbook of Hope (pp. 89-108). Elsevier. https://doi.org/10.1016/b978-012654050-5/50007-5

Spence, G. B., \& Grant, A. M. (2005). Individual and group life coaching: Initial findings from a randomised, controlled trial. In A. Cavanagh, M. Grant, \& T. Kemp (Eds.), Evidence-based coaching, Vol. 1. Theory, research and practice from the behavioural sciences (pp. 143-158). Australian Academic Press.

Tactivos Inc DBA MURAL. (2020). MURAL. San Francisco, CA. https://www.mural.co/

Taylor, J. (2000). Hope as a common factor across psychotherapy approaches: A lesson from the dodo's verdict. In C. R. Snyder (Ed.), Handbook of hope: Theory, measures and applications (pp. 89-107). Academic Press.

Teodorczuk, K., Guse, T., \& du Plessis, G. A. (2019). The effect of positive psychology interventions on hope and well-being of adolescents living in a child and youth care centre. British Journal of Guidance \& Counselling, 47(2), 234-245. https://doi.org/10. $1080 / 03069885.2018 .1504880$ 
Thimm, J. C., Holte, A., Brennen, T., \& Wang, C. E. A. (2013). Hope and expectancies for future events in depression. Frontiers in Psychology. https://doi.org/10.3389/fpsyg.2013.00470

Välimäki, M., Kurki, M., Hätönen, H., Koivunen, M., Selander, M., Saarijärvi, S., \& Anttila, M. (2012). Developing an internetbased support system for adolescents with depression. Journal of Medical Internet Research, 14(6), e22. https://doi.org/10.2196/ resprot. 2263

Valle, M. F., Huebner, E. S., \& Suldo, S. M. (2006). An analysis of hope as a psychological strength. Journal of School Psychology, 44(5), 393-406. https://doi.org/10.1016/j.jsp.2006.03.005

Van Manen, M. (1997). Researching lived experience: Human science for an action sensitive pedagogy. Althouse Press.

Venning, A., Kettler, L., Eliott, J., \& Wilson, A. (2009). The effectiveness of Cognitive-Behavioural Therapy with hopeful elements to prevent the development of depression in young people. International Journal of Evidence-Based Healthcare, 7(1), 15-33. https://doi.org/10.1111/j.1744-1609.2009.00122.x

Veritas Health Innovation. (2020). Covidence systematic review software. Melbourne, Australia: Veritas Health Innovation. www. covidence.org

von Glischinski, M., von Brachel, R., \& Hirschfeld, G. (2019, May 15). How depressed is "depressed"? A systematic review and diagnostic meta-analysis of optimal cut points for the Beck Depression Inventory revised (BDI-II). Quality of Life Research. https:// doi.org/10.1007/s11136-018-2050-x

Walsh, S. M. (1993). Future images: An art intervention with suicidal adolescents. Applied Nursing Research, 6(3), 111-118. https:// doi.org/10.1016/S0897-1897(05)80171-5

Walsh, S. M., \& Hardin, S. B. (1994). An Art Future Image intervention to enhance identity and self-efficacy in adolescents. Journal of Child and Adolescent Psychiatric Nursing, 7(3), 24-34. https://doi.org/10.1111/j.1744-6171.1994.tb00201.x

Walsh, S. M., \& Minor-Schork, D. (1997). Suicidal adolescent perceptions after an art future image intervention. Applied Nursing Research, 10(1), 19-26. https://doi.org/10.1016/S0897-1897(97) 80045-6

Watsford, C., Rickwood, D., \& Vanags, T. (2013). Exploring young people's expectations of a youth mental health care service. Early Intervention in Psychiatry, 7(2), 131-137. https://doi.org/ 10.1111/j.1751-7893.2012.00361.x

Weis, R., \& Ash, S. E. (2009). Changes in adolescent and parent hopefulness in psychotherapy: Effects on adolescent outcomes as evaluated by adolescents, parents, and therapists. The Journal of Positive Psychology, 4(5), 356-364. https://doi.org/10.1080/ 17439760902992381

Weis, R., \& Speridakos, E. C. (2011). A meta-analysis of hope enhancement strategies in clinical and community settings. Psychology of Well-Being: Theory, Research and Practice, 1(1), 5. https://doi.org/10.1186/2211-1522-1-5

Weitkamp, K., Klein, E., Hofmann, H., Wiegand-Grefe, S., \& Midgley, N. (2017). Therapy expectations of adolescents with depression entering psychodynamic psychotherapy: A qualitative study. Journal of Infant, Child, and Adolescent Psychotherapy, 16(1), 93-105. https://doi.org/10.1080/15289168.2016.1268883

Whitaker, D. J., Miller, K. S., \& Clark, L. F. (2000). Reconceptualizing adolescent sexual behavior: Beyond did they or didn't they? Family Planning Perspectives, 32(3), 111. https://doi.org/10.2307/ 2648159

Young, A. S., Grusky, O., Sullivan, G., Webster, C. M., \& Podus, D. (1998). The effect of provider characteristics on case management activities. Administration and Policy in Mental Health, 26(1), 21-32. https://doi.org/10.1023/A:1021213219213

YoungMinds. (2020). Coronavirus: Impact on young people with mental health needs. London. https://youngminds.org.uk/media/ 3708/coronavirus-report_march2020.pdf

Zauszniewski, J. A., \& Graham, G. C. (2009). Comparison of short scales to measure depressive symptoms in elders with diabetes. Western Journal of Nursing Research, 31(2), 219-234. https:// doi.org/10.1177/0193945908326065

Zigmond, A. S., \& Snaith, R. P. (1983). The Hospital Anxiety and Depression Scale. Acta Psychiatrica Scandinavica, 67(6), 361370. https://doi.org/10.1111/j.1600-0447.1983.tb09716.x

Zilcha-Mano, S., Dolev, T., Leibovich, L., \& Barber, J. P. (2018). Identifying the most suitable treatment for depression based on patients' attachment: Study protocol for a randomized controlled trial of supportive-expressive vs. supportive treatments. BMC Psychiatry. https://doi.org/10.1186/s12888-018-1934-1

Zoom Video Communications Inc. (2020). Zoom. San Jose, CA. https://zoom.us/

Publisher's Note Springer Nature remains neutral with regard to jurisdictional claims in published maps and institutional affiliations. 